\title{
Contribution of Inhibitor of DNA Binding/Differentiation-3 and Endocrine Disrupting Chemicals to Pathophysiological Aspects of Chronic Disease
}

\author{
Vincent Avecilla, Mayur Doke, and Quentin Felty \\ Department of Environmental \& Occupational Health, Florida International University, Miami, FL, USA \\ Correspondence should be addressed to Quentin Felty; feltyq@fiu.edu
}

Received 22 November 2016; Revised 15 February 2017; Accepted 29 May 2017; Published 13 July 2017

Academic Editor: Koichiro Wada

Copyright (C) 2017 Vincent Avecilla et al. This is an open access article distributed under the Creative Commons Attribution License, which permits unrestricted use, distribution, and reproduction in any medium, provided the original work is properly cited.

\begin{abstract}
The overwhelming increase in the global incidence of obesity and its associated complications such as insulin resistance, atherosclerosis, pulmonary disease, and degenerative disorders including dementia constitutes a serious public health problem. The Inhibitor of DNA Binding/Differentiation-3 (ID3), a member of the ID family of transcriptional regulators, has been shown to play a role in adipogenesis and therefore ID3 may influence obesity and metabolic health in response to environmental factors. This review will highlight the current understanding of how ID3 may contribute to complex chronic diseases via metabolic perturbations. Based on the increasing number of reports that suggest chronic exposure to and accumulation of endocrine disrupting chemicals (EDCs) within the human body are associated with metabolic disorders, we will also consider the impact of these chemicals on ID3. Improved understanding of the ID3 pathways by which exposure to EDCs can potentiate complex chronic diseases in populations with metabolic disorders (obesity, metabolic syndrome, and glucose intolerance) will likely provide useful knowledge in the prevention and control of complex chronic diseases associated with exposure to environmental pollutants.
\end{abstract}

\section{Introduction}

Inhibitor of DNA Binding/Differentiation-3 is a member of the ID family of helix-loop-helix proteins encoded by an immediate-early gene responsive to mitogenic signals and oxidative stress. ID3 functions as a transcriptional regulator known to prevent stem cell differentiation and promote cell cycle progression. An increasing body of evidence suggests that ID3 may be involved in metabolic perturbations characterized by insulin resistance, hyperglycemia, abdominal obesity, dyslipidemia, and hypertension. Interactions across multiple organ systems that contribute to metabolic perturbations present a challenge to ongoing research attempting to elucidate biological mechanisms of chronic disease associated with metabolic health. For instance, insulin resistance and systemic low-grade inflammation result from complex interactions between the vasculature, metabolic tissue, and immune cells. With regard to these interactions, it is noteworthy that ID3 plays a significant role in vasculogenesis, energy metabolism, and development of the immune system. In the vasculature, ID3 is essential to embryonic vasculogenesis and endothelial cell activation [1-3]. Given that metabolic perturbations are observed in endothelial cells from diseased vasculature [4], ID3 may mediate endothelial dysfunction often found in individuals with metabolic syndrome. In addition to the vasculature, ID3 function spans to metabolic tissue and immune cells. In vivo studies have demonstrated that ID3 mediates high fat diet-induced obesity and promotes obesity-induced inflammatory macrophage accumulation [5, 6]. Thus, we intend to discuss the current understanding of how ID3 may influence chronic diseases associated with metabolic perturbations. Since adipose tissue is an endocrine organ as well as a metabolic organ, exposure to endocrine disrupting chemicals (EDCs) may also contribute to metabolic perturbations associated with chronic disease. EDCs are mostly synthetic chemicals ubiquitously found in our environment that act by altering hormone action. Estrogenic EDCs such as diethylstilbestrol (DES), bisphenol 
A (BPA), estrogenic polychlorinated biphenyls (PCBs), and phthalates have been implicated to interfere with metabolic health during critical periods of development and into adulthood. Epidemiological studies have reported associations between exposure to EDCs and metabolic syndrome [7-9]. Based on our recent findings that showed ID3 dependent endothelial cell activation by exposure to estrogenic PCB congener 153 [10, 11], we will also discuss how low-dose EDC exposure from the environment may potentiate complex chronic disease in populations with metabolic disorders (obesity, metabolic syndrome, and glucose intolerance) via ID3. A better understanding of interactions between ID3 and EDC is critical in deepening our understanding of how environmental factors modify chronic disease risk and health outcomes. Further study in these areas may reveal novel or more effective therapeutic modalities as well as provide prevention and control strategies of complex chronic diseases associated with exposure to EDCs.

\section{Inhibitor of DNA Binding/Differentiation-3 (ID3)}

2.1. Structure and Function. The ID (Inhibitor of DNA Binding/Differentiation) family of small proteins consists of four genes (ID1-ID4). The four members of the ID family share extensive amino acid sequence homology (69-78\%) within their helix-loop-helix (HLH) domain $[12,13]$, but the remaining parts of the proteins are nonrelated. Experimental studies in genetically engineered mice have revealed the importance of ID3 in embryonic development and cell differentiation. ID3 gene knockout mice are viable; however, they have demonstrated defects in immune cell differentiation $[14,15]$. In contrast, double ID1/ID3 knockout mice showed abnormal vascularization of the brain [16], neuronal differentiation, and cardiac defects [17] that were embryonically lethal. Resistance to tumor angiogenesis was reported in mice deficient in 1-3 alleles of ID1/ID3 gene knockout combination [12]. ID3 is highly expressed in embryonic tissue but declines as cells differentiate [12]. In adult tissues, the expression of ID3 is context specific and tends to be highest in proliferating and undifferentiated cells. ID3 expression has been reported to be induced by diverse stimuli in many cell types [18].

The ID3 gene was initially identified as a serum-inducible immediate-early gene in mouse fibroblasts that peaks transcriptionally at $1 \mathrm{~h}[14,19]$. Subsequently, ID3 expression has been reported to be biphasic with maximal stimulation at $1 \mathrm{~h}$ following a second burst at $24 \mathrm{~h}$ as in the case of tissue regeneration after injury. We and others have shown that ID3 expression is redox sensitive $[1,20]$. Specifically, we have shown that vascular endothelial cells exposed to either $17 \beta$-estradiol (E2) or the estrogenic PCB congener 153 (PCB153) resulted in increased ID3 expression, protein phosphorylation, and endothelial neovascularization. Treatment with reactive oxygen species scavengers inhibited estrogenic chemical induced neovascularization [10, 21]. Proteasomes reportedly degrade ID3 by an ubiquitin dependent mechanism. The protein half-life of ID3 has been demonstrated to be approximately $20 \mathrm{~min}$ in HEK293 cells [13]. In mammals, ID protein-protein interactions occur via the HLH motif in which ID proteins dimerize and block the DNA binding activity of basic HLH transcription factors, such as a group of E proteins (E12/E47, E2-2, and HEB) encoded by the TCF3, TCF4, and TCF12 gene, respectively. Among these E proteins, ID3 has been most often reported to interact with E12/E47 [22]. The E proteins are basic HLH transcription factors that bind to the E-box consensus sequence (CANNTG) in the promoter of target genes. ID3 plays an important role in cell proliferation via its interactions with E proteins. For example, E proteins have been shown to bind the E-box sequence in the promoter of the cyclin dependent kinase inhibitor $\mathrm{p} 21^{\mathrm{Cip} 1}$ and activate its transcription [23]. The level of $\mathrm{p} 21^{\mathrm{Cip} 1}$ is elevated in quiescent cells where it acts as a suppressor of cell proliferation [24]. In the context of the cell cycle, ID3 promotes cell cycle progression by the inhibition of $\mathrm{p} 21^{\mathrm{Cip} 1}$ expression [25]. Specifically, ID3 protein-protein interactions with $\mathrm{E}$ proteins can disrupt their ability to bind gene promoters and thereby block transcriptional activation by these factors. ID3 has been shown to inhibit $\mathrm{E}$ proteins from activating the $\mathrm{p} 21^{\mathrm{Cip} 1}$ promoter in proliferating vascular cells [26]. Thus, ID3 has been frequently described as a dominant negative inhibitor of E proteins. Although ID proteins have been shown to function as dominant negative transcriptional regulators of E proteins, there may be circumstances by which ID3 acts as a positive transcriptional regulator. ID3 has been shown to regulate the binding of transcription factor 3 (TCF3) to the E-box motif in target gene promoters [27]. TCF3 has been reported to repress the expression of pluripotency genes OCT4, SOX2, and NANOG that contribute to cell differentiation [14]. Our research has shown that ectopic overexpression of ID3 increased OCT4 and SOX2 expression in endothelial cells and resulted in a population of cells that were positive for the molecular stemness signature $\mathrm{CD} 133^{+}$VEGFR3 $^{+} \mathrm{CD} 4^{+}$[28]. These endothelial stem cells were morphologically differentiated into smooth muscle cells and neuron cells. Based on these lines of evidence, ID3 maintains cells in an undifferentiated or noncommitted state by preventing the repression of pluripotency factors by TCF3. Hence, it is also plausible for ID3 to function as a positive regulator of gene transcription. In lieu of a recent report that showed ID3 to modulate genes essential for maintaining genome integrity during cell division [29], a dual regulatory role of ID3 in both positive and negative gene transcription expands its influence as shown in Figure 1. ID3 proteinprotein interactions are not exclusive to $\mathrm{E}$ proteins as ID proteins have also been reported to bind to proteins that do not contain the HLH motif such as caveolin-1 [30].

2.2. ID3 and Metabolic Syndrome (MetS). There has been increasing evidence that ID3 plays a role in adipogenesis. ID3 through adiponectin is considered to improve $\beta$-cell function, circulating lipids, and insulin sensitivity levels [31, 32]. ID3 inhibits transcriptional activity of E47 in undifferentiated preadipocytes [6]. ID3 negatively inhibits the FAS (fatty acid synthase) promoter via SREP-1c in adipose tissue. ID3 furthermore plays a role in blood glucose, which if dysregulated can lead to insulin resistance. In human islet cells ID1 and ID3 mRNA levels are increased with addition of 


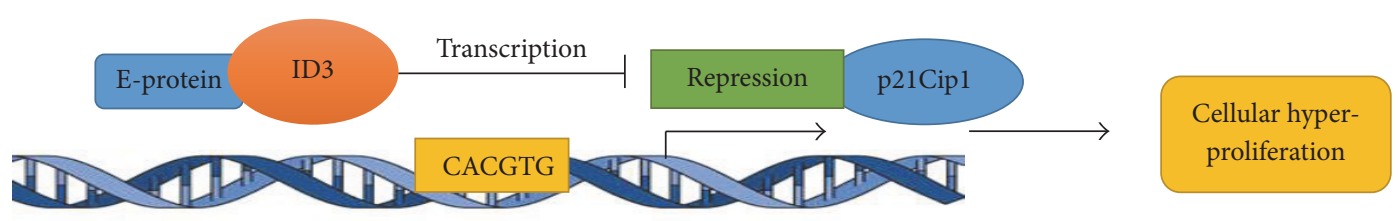

(a)

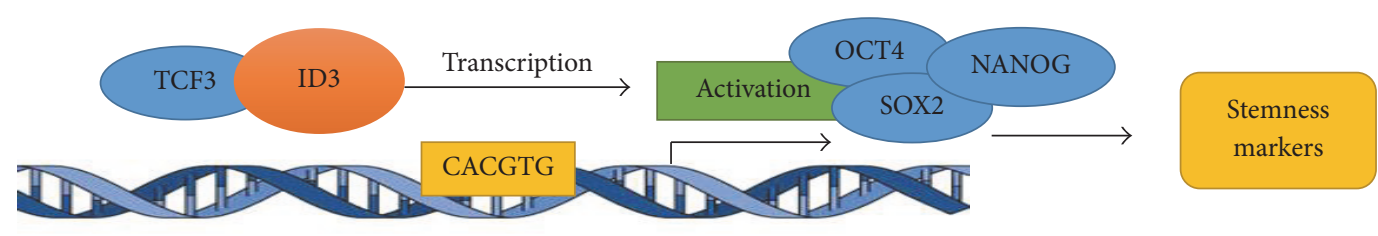

(b)

FIGURE 1: ID3 transcriptional regulation. Scheme illustrating how ID3 can repress expression of p21 gene (a) or activate gene expression of embryonic transcription factors (b).

glucose [33]. The induction of ID1 and ID3 expression, insulin secretion, and gene transcription suggests that IDs may play a role in promoting $\beta$-cell function $[33,34]$.

\subsection{ID3 and Endocrine Disrupting Chemicals Influence} Metabolic Perturbation. Metabolic syndrome (MetS) and its associated complications such as insulin resistance, abdominal obesity, dyslipidemia, and hypertension contribute to chronic diseases including cardiovascular disease (CVD), type 2 diabetes, cancer, and chronic kidney disease (CKD). Some studies have shown the prevalence of MetS in the United States at approximately $34 \%$ of the adult population [35]. MetS is an illness of energy consumption and storage which is a diagnosis of the cooccurrence of a minimum of three of the following medical conditions: abdominal obesity, high triglyceride levels, low HDL cholesterol levels, high fasting blood sugar, and high blood pressure. The molecular mechanisms of MetS are not fully understood. Most patients are older, sedentary, and obese and have a certain amount of insulin resistance. Important factors that are associated with MetS can include aging, diet, sedentary behavior, genetics, excessive alcohol use, or low physical activity [16, 36-38]. MetS appears to have three conceivable etiological groupings: obesity and disorders of adipose tissue; insulin resistance; and a collection of independent factors (e.g., molecules of hepatic, vascular, and immunologic origin).

Inflammatory factors produced during obesity are a major pathway for developing metabolic perturbation which can lead to MetS. Experimental studies have demonstrated ID3 to be a key regulator of monocyte chemoattractant protein-1 (MCP-1) [39]. MCP-1 is a well-known chemokine impacted by MetS [40]. ID3 has also been reported to regulate the production of interleukins IL-5, IL-6, IL-8, and IL-10 [41-43]. The induction of these chemokines has been observed in population studies of obesity and/or MetS. ID3 is also an oxidative stress regulated gene which may provide a positive feedback pathway in response to metabolic perturbations $[1,20]$. Taken together, these lines of evidence provide the basis for how ID3 can participate in metabolic perturbations via controlling the expression of inflammatory factors involved in obesity and/or MetS. A growing number of reports implicate endocrine disrupting chemicals (EDCs) as an environmental factor that contributes to the occurrence of MetS. We performed a comprehensive search in the Comparative Toxicogenomic Database (CTD) to identify known ID3 and EDC interactions with results shown in Table 1 [44].

Adipose tissue is highly connected to steroid hormones (estrogens, androgens, and glucocorticoids) and maintains a close relationship with the immune system via adipokines. Endocrine disruption can interfere with the creation, discharge, breakdown, elimination, and imitation of natural hormones [45]. EDCs can be cataloged into multiple groupings such as dioxins, organotins, plastics, and pesticides. The increased presence of EDCs in the environment may help explain the incidence of metabolic disorders and associated complications. EDCs are found in everyday products (including food, plastic bottles, metal cans, toys, cosmetics, and pesticides) and used in the manufacture of food. Exposure to EDCs may regulate inflammatory factors via ID3. TCDD and PCB congeners have been shown to upregulate MCP1 expression [46]. Bisphenol A exposure has been reported to increase IL-6 [47]. Population studies furthermore have reported an association between bisphenol A plasma levels and proinflammatory cytokines including IL-6 [48].

Besides inflammation, ID3 may contribute to other risk factors of MetS such as angiogenesis, adipose tissue, blood glucose levels, and insulin resistance. PCBs have been associated with MetS in epidemiological studies [49]. In the mouse model, PCB153 has been shown to produce significant metabolic changes when administered with a high fat diet that were consistent with worsened obesity and nonalcoholic fatty liver disease pathology [50]. ID3 may contribute to MetS via visceral fat expansion that was demonstrated in mice fed a high fat diet [5]. ID3 deficiency resulted in greater energy expenditure and higher metabolic rate in mice at rest. With respect to metabolic disorders involving high glucose levels, ID3 may be impacted because it was shown 


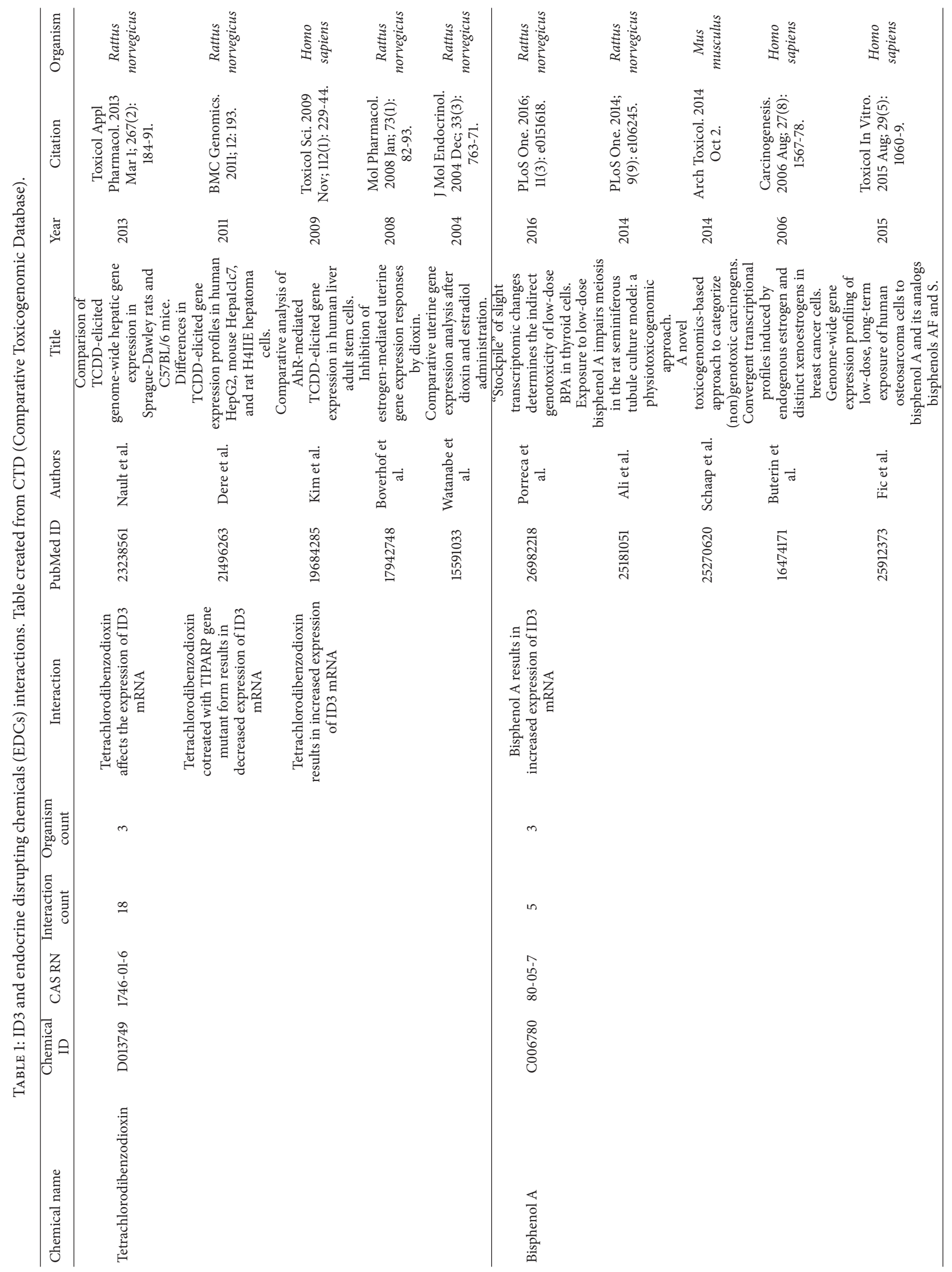




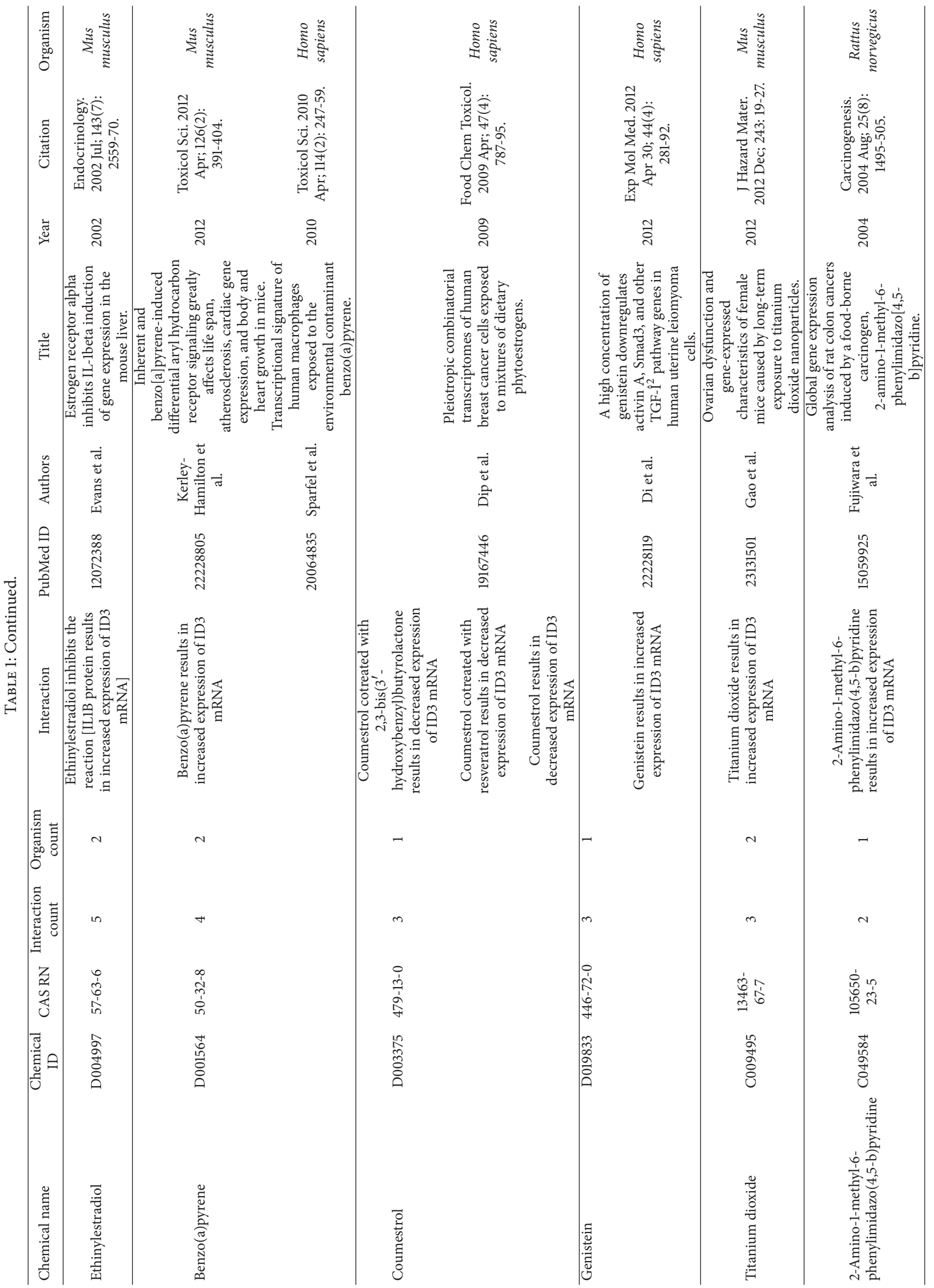




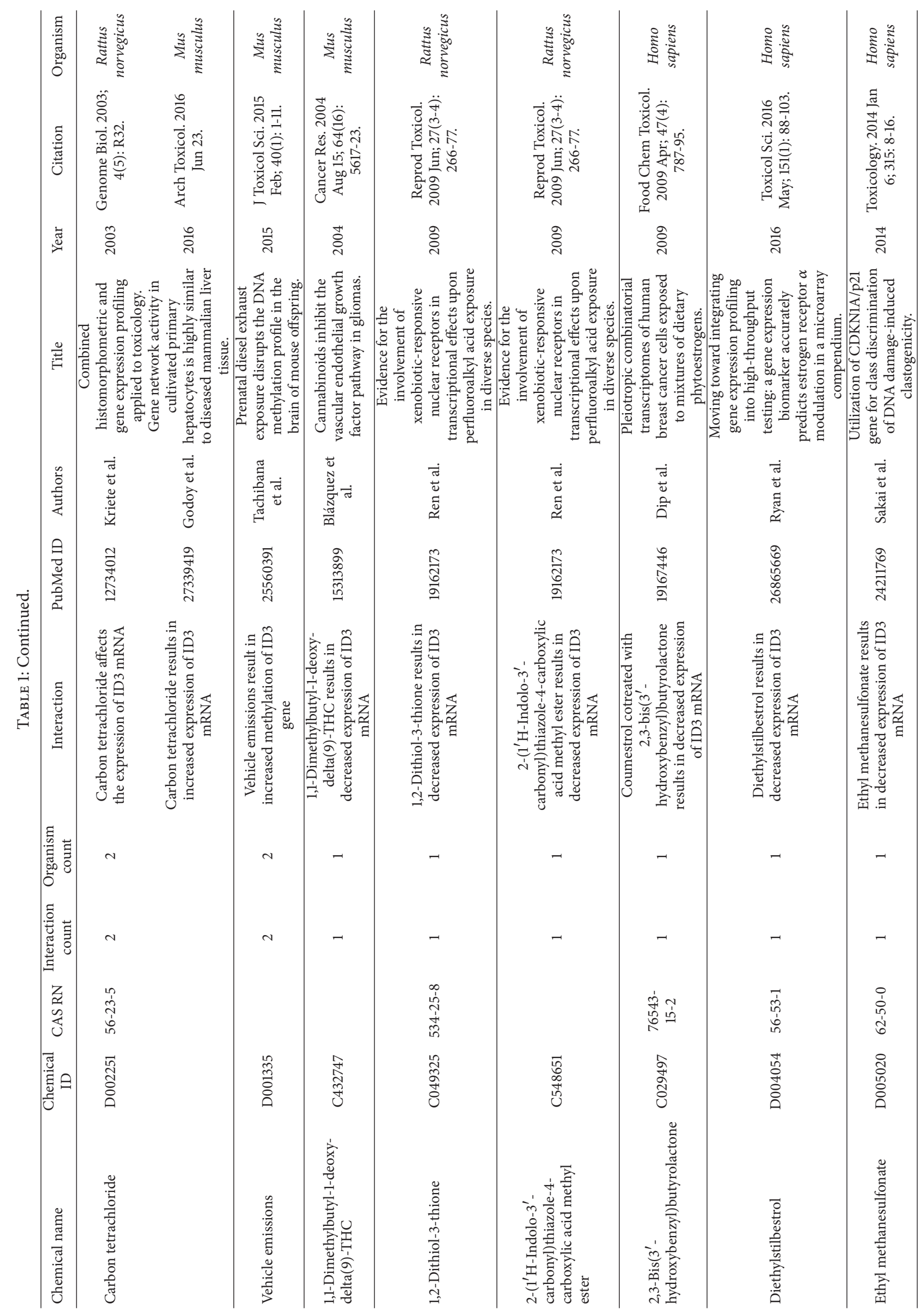




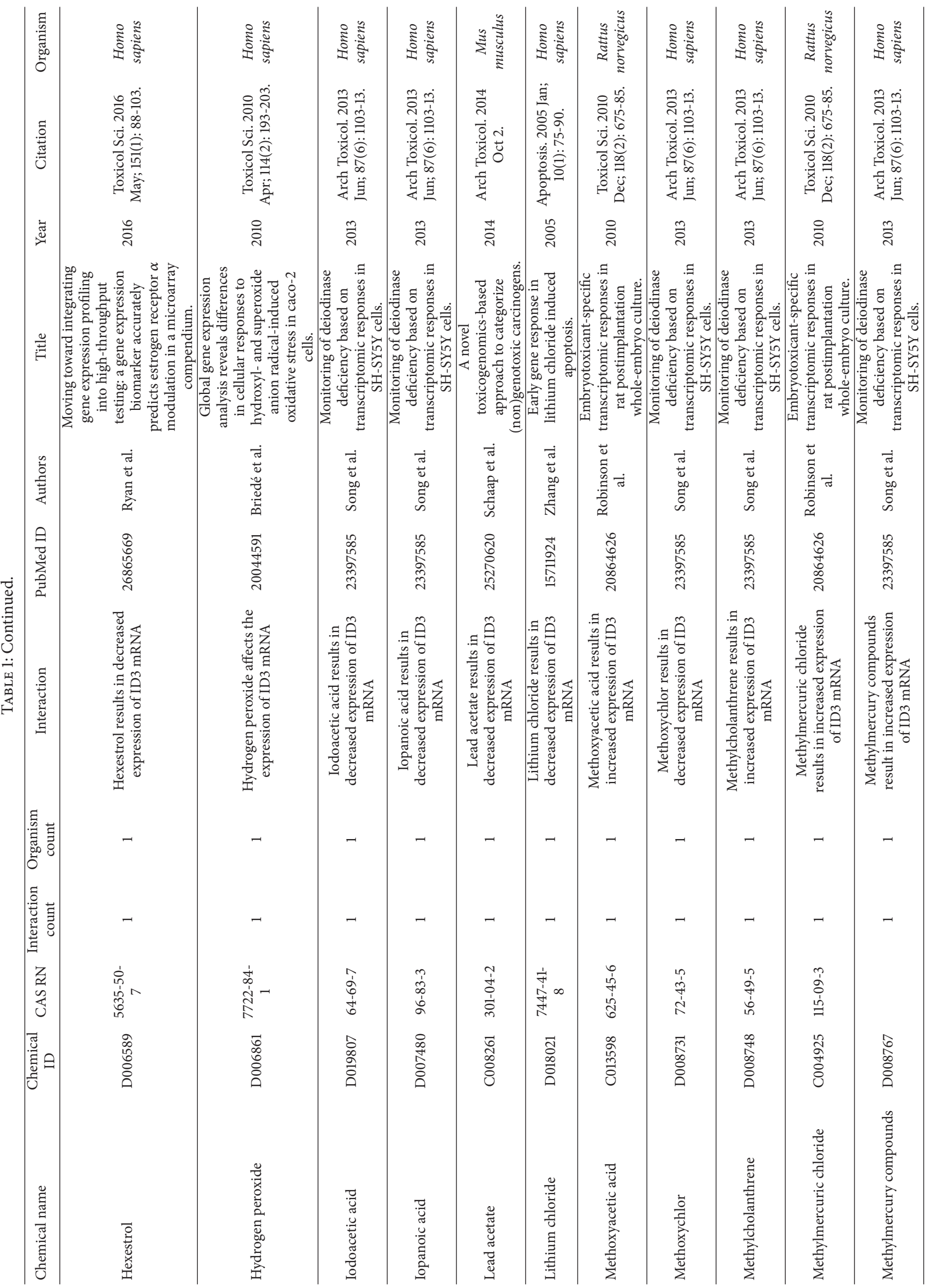




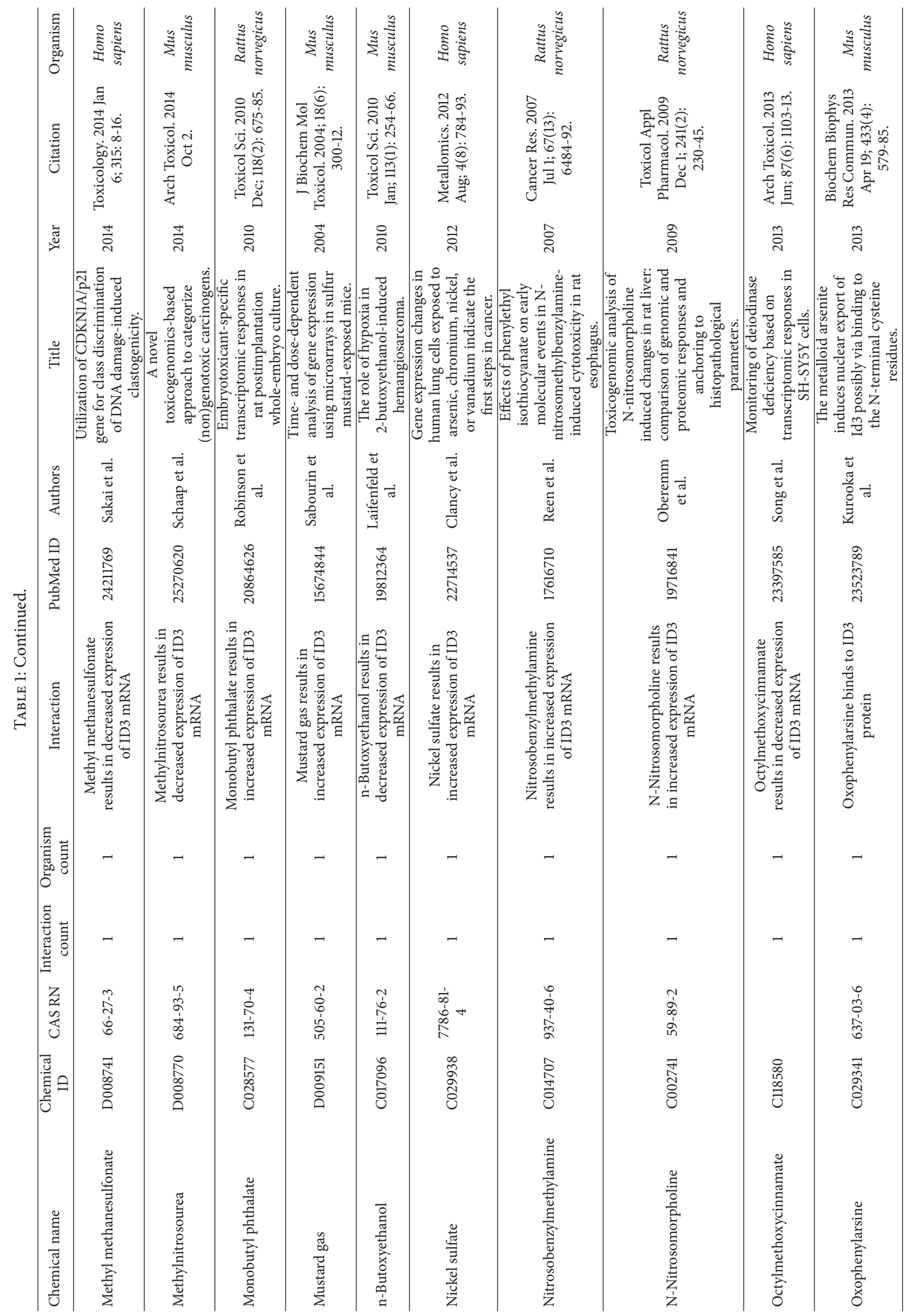




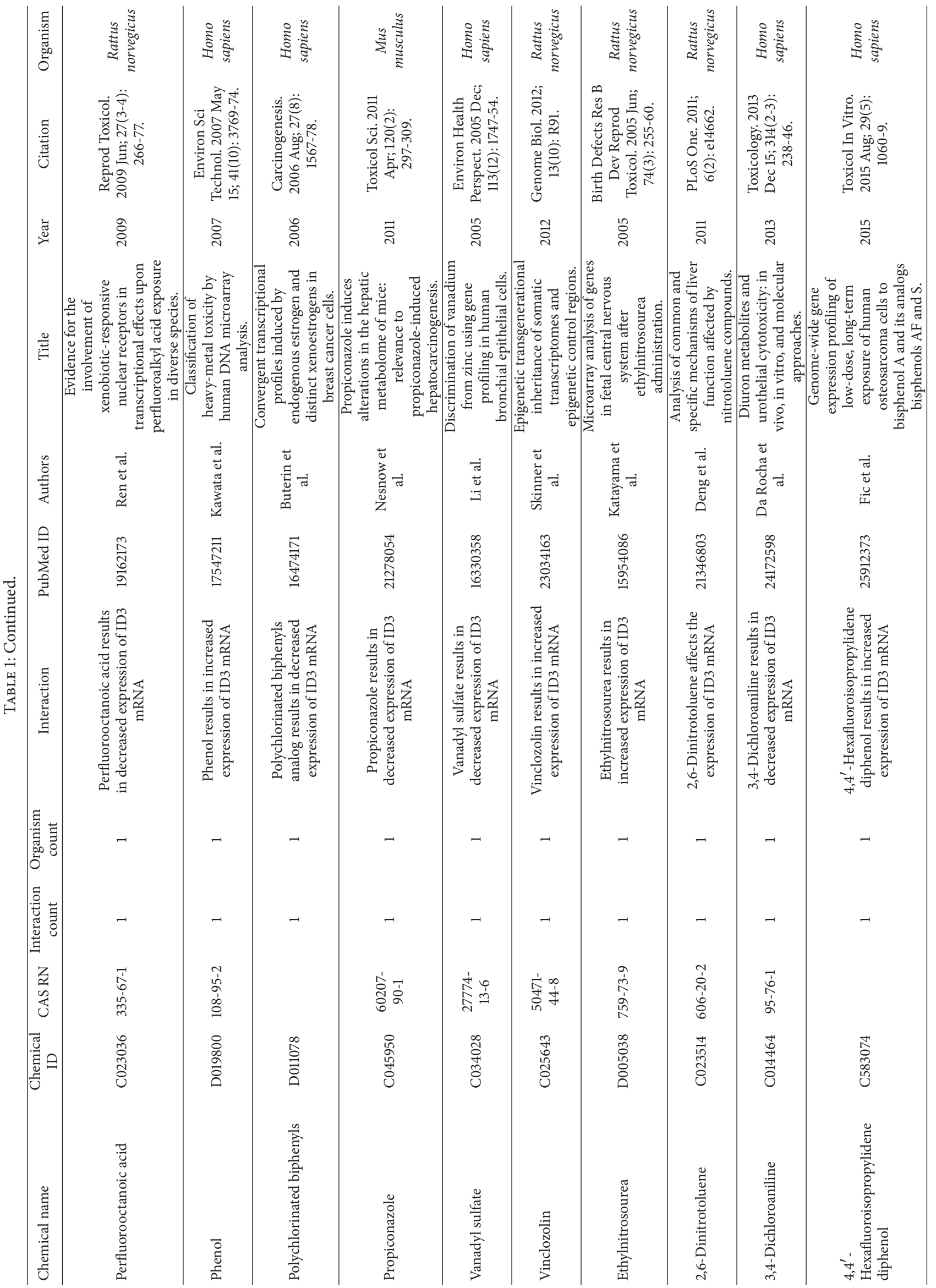




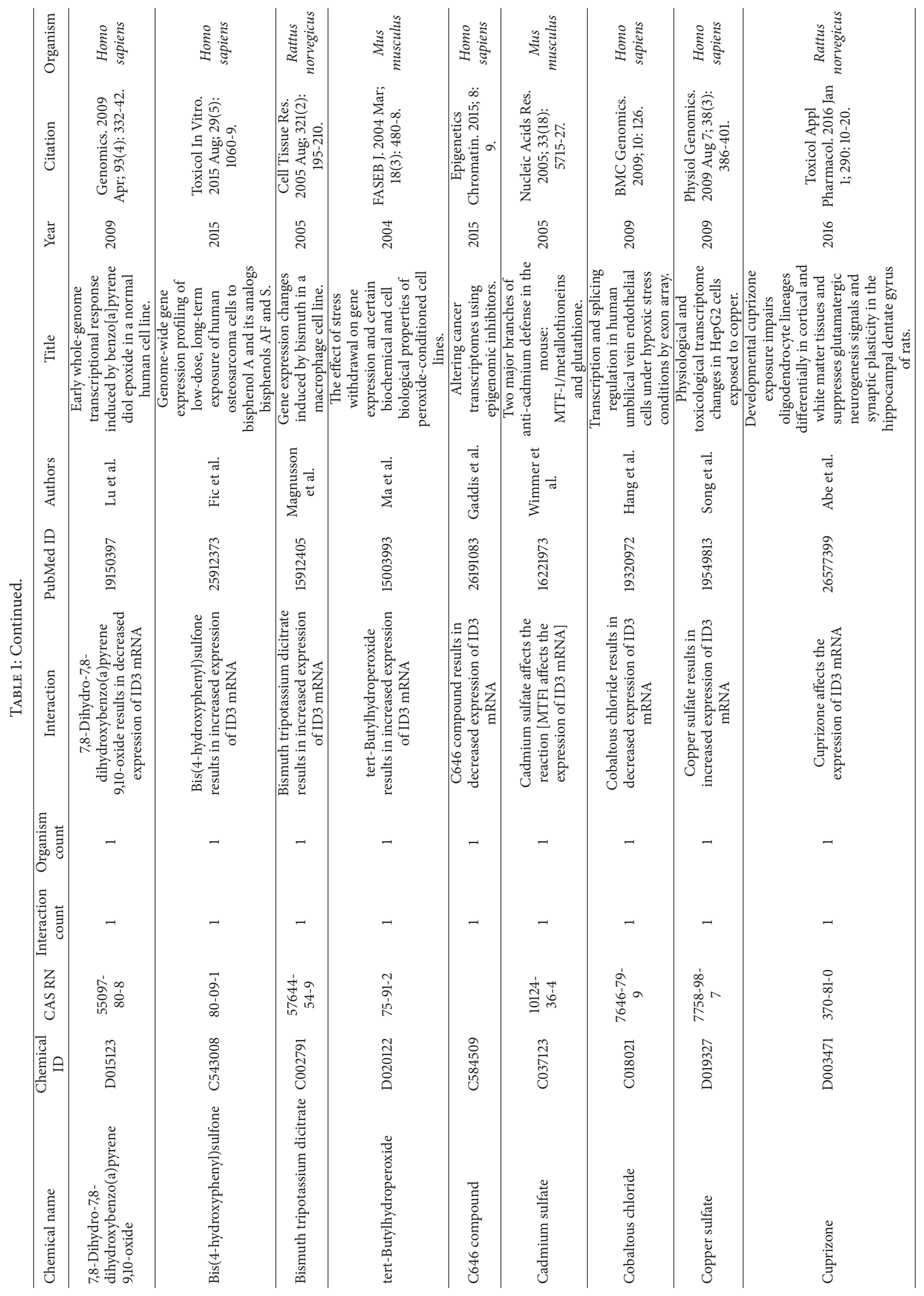




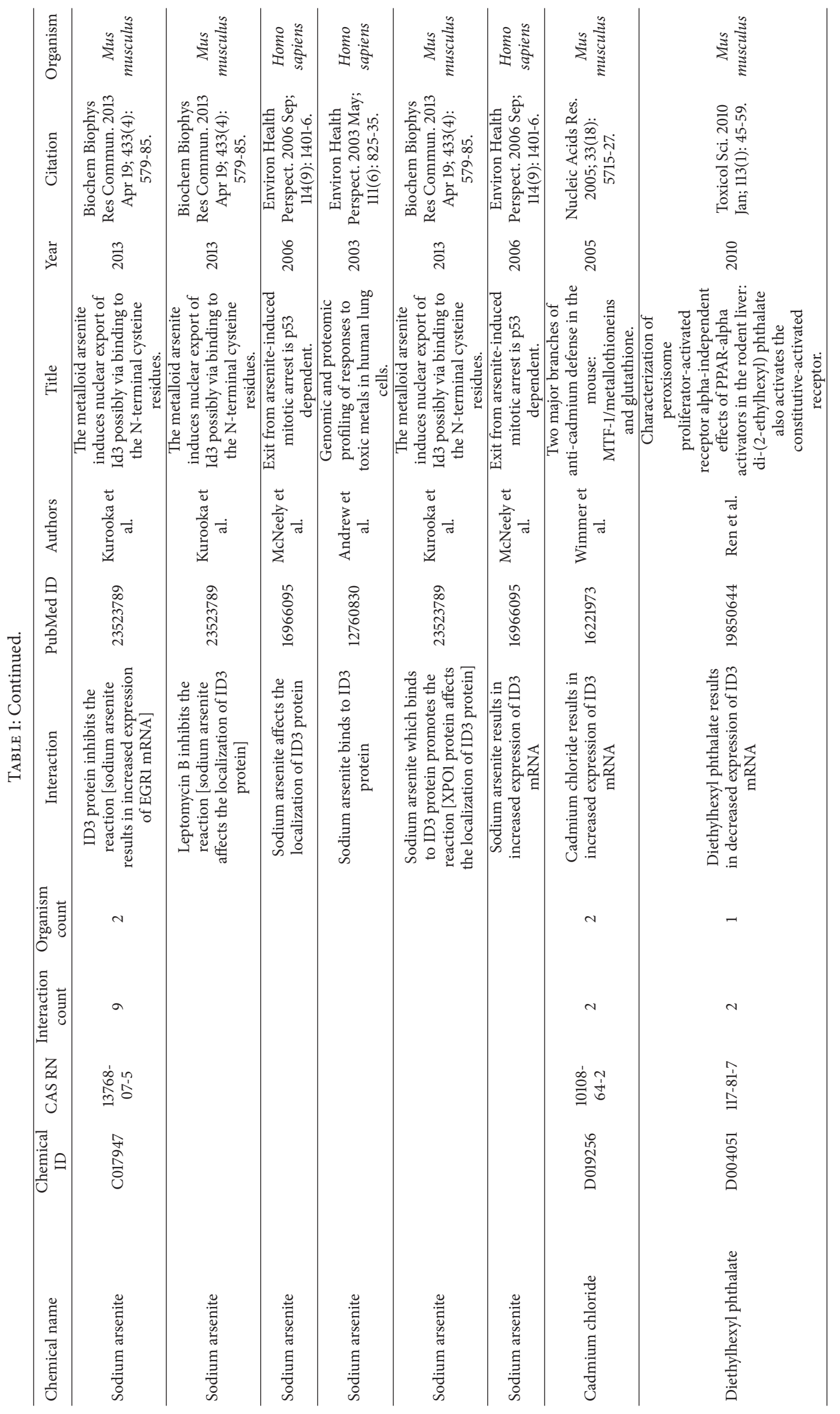


to be regulated by glucose in pancreatic islet $\beta$-cells [33] and under chronic hyperglycemic conditions. ID family proteins were stabilized which in turn activated metabolic genes [51]. Since a causal link of diabetes and vascular disease is chronic hyperglycemia, ID3 may also contribute to metabolic perturbations from high blood glucose levels. More importantly, however, mitochondrial reactive oxygen species (ROS) produced by vascular endothelial cells under hyperglycemic conditions may share a pathway similar to environmental toxicant induced oxidative stress which converges on ID3. PCBs have been reported to have estrogenic activity [5255]. PCB153 is an agonist for the pregnane $X$ receptor (PXR) and the constitutive androstane receptor (CAR) which exert their effects on energy metabolism through gene regulation [56]. Hence, dysregulation of these receptors by EDCs may contribute to PCB-induced metabolic perturbations. Several epidemiological studies have reported the association of PCB exposure with the increased risk of cardiovascular disease [57-61]. Since cardiovascular disease is a chronic disease affected by metabolic perturbations, we investigated the effects of PCB153 exposure on ID3 in vascular cells. Based on known PCB blood levels from occupational exposure, we showed a significant increase in PCB153-induced vascularization at doses of $10-100 \mathrm{ng} / \mathrm{mL}$ which was ID3 dependent [11]. We have shown that PCB-induced ROS mediated a highly branched neovascular phenotype depending on ID3 and Pyk2 [10]. Because the level of ID3 protein is determined by the rates of protein synthesis and protein degradation, we tested if PCB153 treatment affected ID3 protein synthesis. We showed that estrogenic chemical induced ID3 did not depend on protein synthesis; instead PCB153 treatment increased ID3 protein stability in endothelial cells. The role of phosphorylation in the regulation of ID3 protein stability is not known. A search with the PhosphoMotif finder program revealed that ID3 had 38 serine kinase/phosphatase motifs and 8 tyrosine kinase/phosphatase motifs [62]. We reported that both E2 and PCB153 induced ID3 phosphorylation. E2 treatment stabilized ID3 protein during the $1-6 \mathrm{~h}$ treatment time points and increased phosphorylated ID3 levels [10, 21]. It was noteworthy that we showed data of ID3 tyrosine phosphorylation by PCB153 treatment which was confirmed by MALDI-TOF MS/MS spectra data. Our findings revealed phosphorylated amino acids Tyr-11 and Tyr-48 in peptides from ID3. Interestingly, Tyr-48 is positioned in the helixloop-helix motif that is essential for protein binding. Currently, it is not clear whether PCB153-induced phosphoID3 leads to protein-protein interactions that may prevent its degradation; however, our findings demonstrated that ID3 is a target of posttranslational modifications by the endocrine disruptor PCB153 in vascular endothelial cells. Based on these lines of evidence, estrogenic chemical induced ID3 signaling contributes to hyperplastic vascular lesions. This vascular cell dysfunction may be a pathway by which EDCs and ID3 contribute to cardiovascular disease [1]. Based on these findings, we propose that ID3 is a target of EDCs that can activate inflammatory and energy pathways susceptible to metabolic perturbation during chronic disease pathogenesis. In the next section, we intend to discuss the current mechanistic understanding of how ID3 may influence chronic diseases associated with metabolic perturbations.

\section{ID3 and Disease Outcomes}

3.1. Vascular Diseases. ID3 involvement in vascular disease has been studied together with the lipoxygenase (12/15-LO) which is known to generate proinflammatory changes in blood vessels that precede the development of atherosclerosis [63]. 12/15-LO is an important mediator of VSMC growth and its growth-promoting effects were shown to be mediated by ID3 transcription [64]. Increased expression of 12/15LO in the vessel wall enhanced ID3-dependent cell proliferation, fibronectin deposition, and neointimal formation. Population-based studies have found SNP (single nucleotide polymorphisms) rs11574 in the coding region of the human ID3 gene associated with subclinical atherosclerosis in the Diabetes Heart Study [65]. ID3 SNP rs11574 showed a significant association of coronary artery disease for Caucasians and to a lesser extent African Americans and Hispanics [66]. Ectopic expression of ID3 in VSMC (vascular smooth muscle cells) regulates the cell cycle [67]. ID3 has also been shown to play a complex role with atherosclerosis. ID3 expression is increased by hyperlipidemia and oxidized LDL [26]. ID3 regulates angiotensin II and carotid intima-media thickness. Angiotensin II promotes hyperplasia through upregulating ID3 [68]. The ID3 SNP could be a potential loss of function mutation if it inhibits the functioning of $\mathrm{E}$ proteins, thus being an atheroprotective factor. As shown in Figure 2, ID3 may impact vascular cell dysfunction leading to intimal lesions.

ID3 stimulates visceral adipose VEGFA expression, depot expansion, and microvascular blood volume [5]. ID3 promotes angiogenesis in HFD- (high fat diet-) induced visceral adiposity [5]. ID3 KO shows a protective effect from HFDinduced visceral fat depot expansion. Furthermore, HFDinduced VEGFA expression in visceral adipose tissue was completely abolished by loss of ID3. BMP9 induces both ID1 and ID3 which are necessary for induction of Ephrin B2 [69]. A summary in Figure 2(b) shows an ID3 signaling pathway involved in vascular malformations.

3.2. Neurological Disorders. The ID3 gene is biologically relevant to neurological and behavior research because of its involvement in the stress response, neural plasticity, and neural circuitry. Molecular genetic studies in mice have shown that ID3 is required for embryonic neurovascular development. Genetic loss of ID1 and ID3 led to deviant neurovascular formations resulting in death [12]. ID1 and ID3 mutants showed premature differentiation of CNS radial glial cells that greatly increased neurons. Since radial glial cells function as scaffolds for developing blood vessels in the CNS, alterations to their development in ID1/ID3 knockout mice may contribute to deviant blood vessel morphogenesis and hemorrhage. ID1 and ID3 may function beyond maturation of the CNS neurovasculature because other pathways such as Notchl activation do not support neurovascular disorders [70, 71]. Psychopathologies such as anxiety and depression have been associated with ID3 methylation status. Epigenetic 


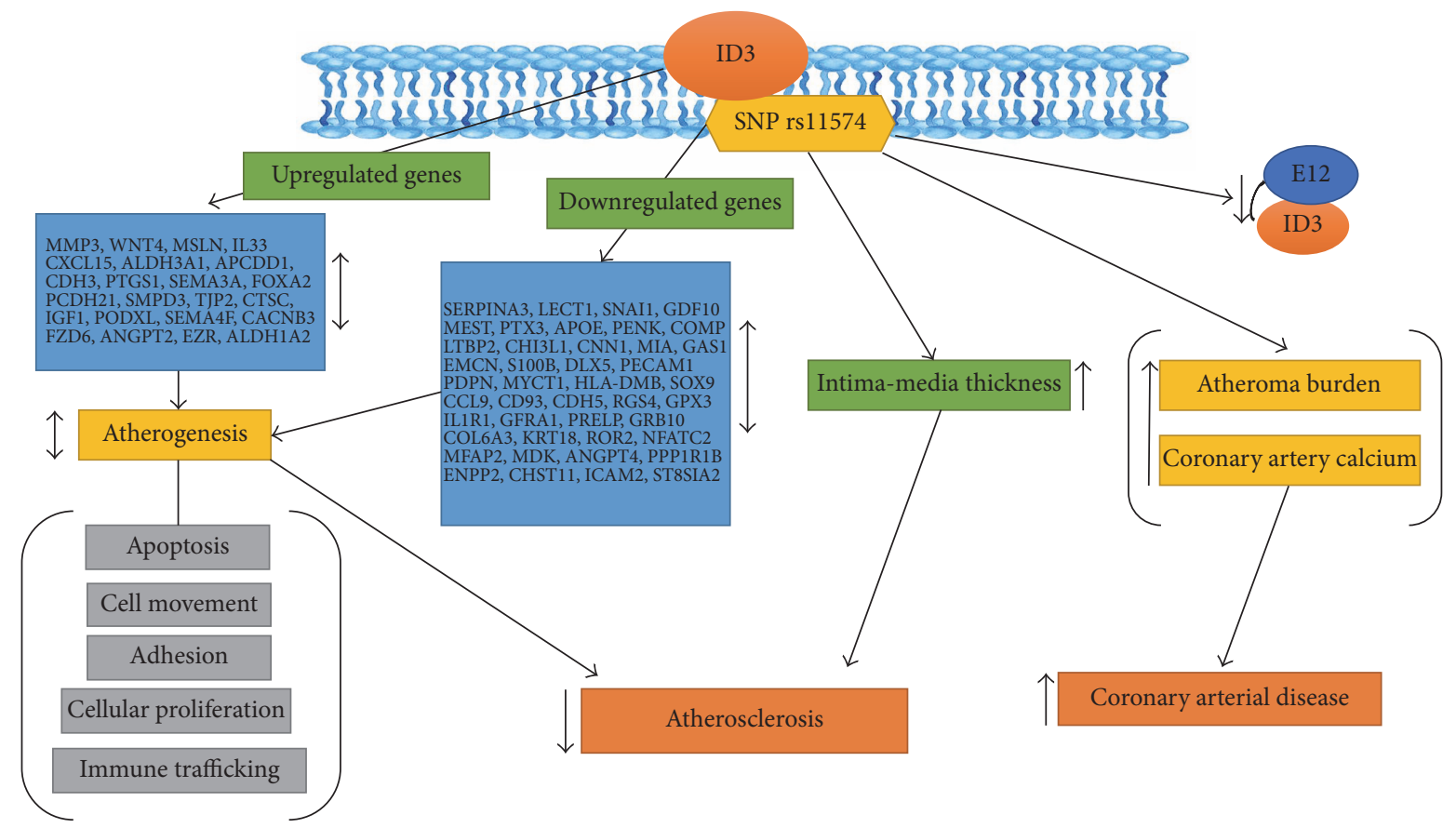

(a) ID3 molecular mechanism and vascular diseases. Summary illustration of ID3 signaling involved in vascular disease pathogenesis. ID3 signaling can lead to neointimal lesions or vascular remodeling by transcriptional regulation of the target genes described above (up- and down regulated genes by ID3)

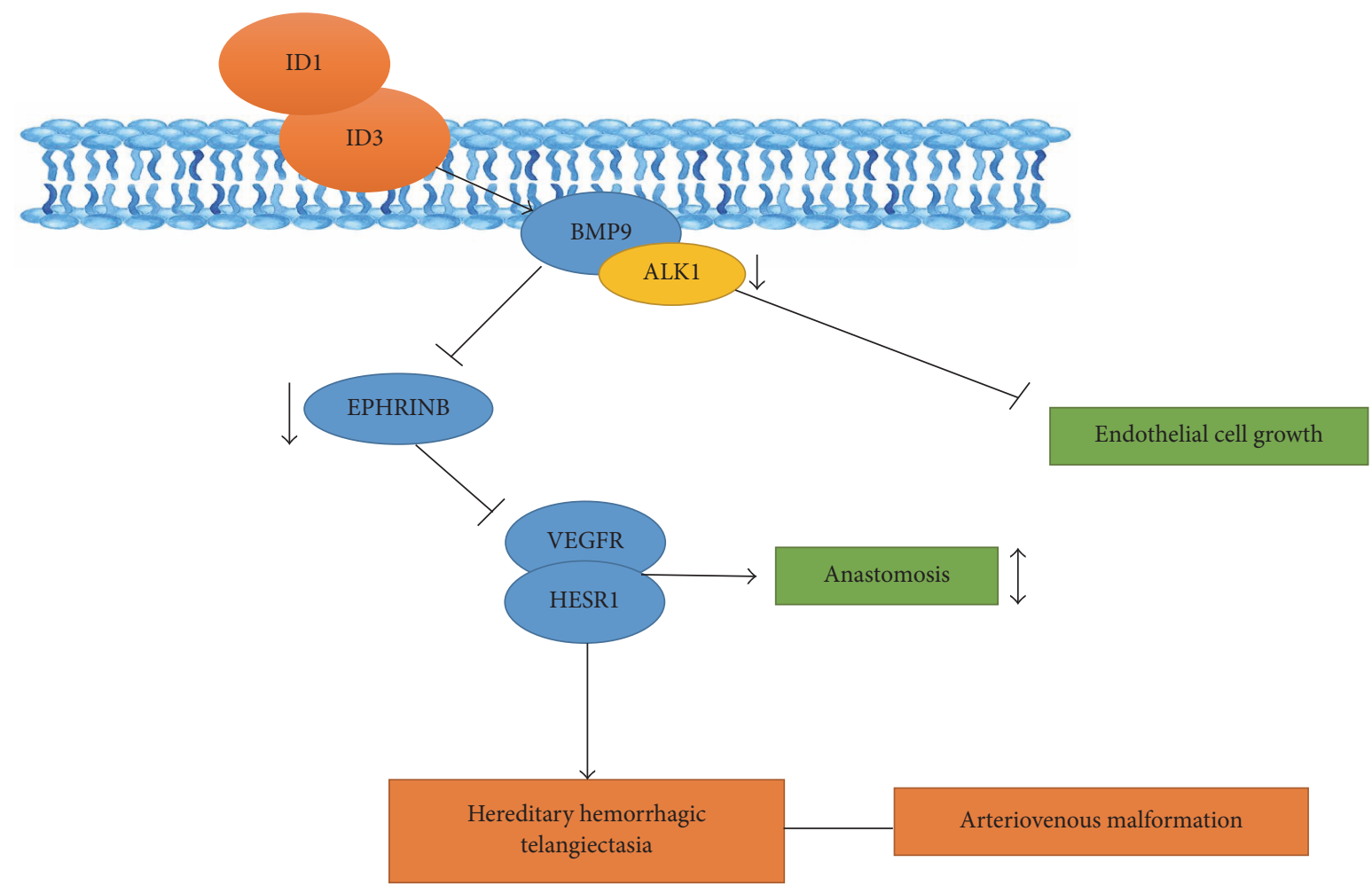

(b) ID3 involvement in arteriovenous malformation. Summary of experimental studies showing impact of ID3 in vascular cell dysfunction

FIGURE 2 
changes in ID3 have been associated with maltreatment of children and demonstrated as a predictor for depression. Montalvo-Ortiz et al. reported epigenetic alterations in DNA derived from saliva in three genes predicted depression in a cohort of maltreated children: ID3, Glutamate NMDA Receptor (GRIN1), and Tubulin Polymerization Promoting Protein (TPPP) [72]. Studies of the expression of these genes from medial prefrontal cortex (mPFC) tissue of mice are subjected to a model of maternal neglect, which comprised maternal separation and early weaning (MSEW). Behavioral tests were performed in MSEW and control adult male mice by the higher plus maze (EPM) and forced swimming test (FST), respectively [72]. Behavioral differences in the EPM and FST tests showed that these genes, ID3, GRIN1, and TPPP, could predict anxiety and depression. Based on these studies, ID3 may contribute to the etiology of anxiety and depressive phenotypes when exposed to early life stress [72] (Figure 3(a)).

Both environmental and genetic factors contribute to the progression of MetS and neurodegenerative disorders [73]. Numerous studies have demonstrated that prediabetes and diabetes mellitus support cognitive decline related to Alzheimer's disease (AD) and vascular dementia [73]. For example, sucrose-treated mice develop mitochondrial abnormalities with significant increase in $\mathrm{A} \beta$ levels and slight increase in pTau levels which links metabolic perturbations from sucrose consumption with the AD-like pathology. Epigenetic changes in ID3 have been associated with maltreatment of children and demonstrated as a predictor for depression [74]. Another epigenetic study of individuals with autism spectrum disorders (ASD) revealed a significant association with a microRNA that targets ID3 [75]. This is interesting as ID3 is also a neuronal target of MeCP2 which is the causative gene for Rett syndrome in which afflicted children often exhibit autistic-like behaviors [76]. The overlap in the clinical symptoms of ASD, ADHD, and neurodegenerative disorders raises the question of whether epigenetic regulation of ID3 plays a role.

Population-based studies have demonstrated an association between toxic environmental chemical exposure and impaired neurodevelopment that may impact neurobehavioral disorders [77]. Exposure to air pollutants from traffic and coal emissions is well-known risk factors for both attention deficit hyperactivity disorder (ADHD) and autism spectrum disorders (ASD) [78]. Polychlorinated biphenyls (PCBs) are endocrine disrupting chemicals shown to adversely affect cognitive performance. Children exposed to PCBs have shown behavioral impairments as well as significant deficits in verbal and full-scale IQ [79]. Urban areas are important regional sources of airborne $\mathrm{PCBs}$ and populationscale airborne exposure. Although PCBs have not been intentionally produced in the USA since the late 1970s, they continue to be detected in ambient air samples throughout the world [80]. PCBs are measurable in the blood of nearly $80 \%$ of Americans over age 50 years [81]. Hence, exposure to PCBs has been proposed to disrupt developing neuronal circuits that may cause developmental brain disorders such as learning disorders (LD), ADHD, and autism.

Endothelial cells of the blood-brain barrier (BBB) may provide clues in the study of brain health, behavior, and the environment [4]. Inhaled air pollutants can disrupt the $\mathrm{BBB}$ by inducing proinflammatory cytokines that act on endothelial cells [82]. We have shown evidence for how PCB-induced reactive oxygen species (ROS) may contribute to cerebral vascular phenotype changes with the goal of understanding consequences the environmental exposure has on the BBB [28]. Toxic chemical exposure can change brain gene expression through regulatory epigenetic mechanisms involving alterations in DNA methylation and histone acetylation. Evidence from animal studies show that epigenetic programming by fetal exposure to toxicants has long-lasting consequences for gene expression in the brain as well as behavior [83]. Epigenetic changes in ID3 have been associated with maltreatment of children and demonstrated as a predictor for depression [74]. Epigenetic biomarkers in peripheral tissues (blood, saliva, or buccal cells) may be useful to predict neurodevelopmental disorders in humans. Exposure to prenatal stress, famine, and pollution/toxins, factors known to affect brain development, has been associated with epigenetic variation in human peripheral tissues [84]. Based on these evidences, we postulate that ID3 can be a useful biological marker of epigenetic perturbations caused by toxic chemical exposure in children/adolescents (Figure 3(b)).

3.3. Kidney Disease. Lipoprotein abnormalities have been reportedly linked to renal dysfunction in chronic kidney disease patients. Nackiewicz et al. reviewed the prominent characteristics of kidney disease previously stated in $\mathrm{ApoE}^{-/-} \mathrm{ID}^{-/-}$double knockout mice and show that ID3 in hyperlipidemic mice directly effects vulnerability to kidney disease. ID3 deficiency may intensify CXCL1 production by glomerular cells in response to inflammatory lipids and the resulting macrophage recruitment. Because ID3 is present in multiple cell types, it is also conceivable that other glomerular cells lacking ID3 may contribute to cytokine production in vivo [85]. Therefore, the renoprotective effect of ID3 may be through regulation of local chemokine production. ID3 is known to directly interact with more than 30 different transcription factors [86]. Noticeably, a change in the ID3 function may impact a wide range of protein-protein interactions with potentially significant consequences [87]. In dissimilarity to the findings of Nachkiewicz et al., in $\mathrm{ApoE}^{-/-} \mathrm{ID}^{-/-}$mice with glomerulonephritis, the hyperlipidemic $\mathrm{ID}^{-/-}$mice did not express meaningful increase in glomerular immune complex deposition associated with hyperlipidemic WT mice. Apolipoprotein E deficiency is known to cause enlarged immune responsiveness [88] and these results add significance to the study in dissecting the effects of ID3 alone on kidney disease.

Clinical studies deliver indication for the relationship between lipids and chronic kidney disease. Nevertheless, they fail to elucidate why certain individuals (in the absence of diabetes or MetS) are probable to develop chronic kidney disease [89]. Increased susceptibility to atherosclerosis has been reported to be associated with an ID3 single nucleotide polymorphism (SNP) [65]. The overall preliminary findings in humans suggest a significant association between the same ID3 SNP and proteinuria, specifically influenced by small 


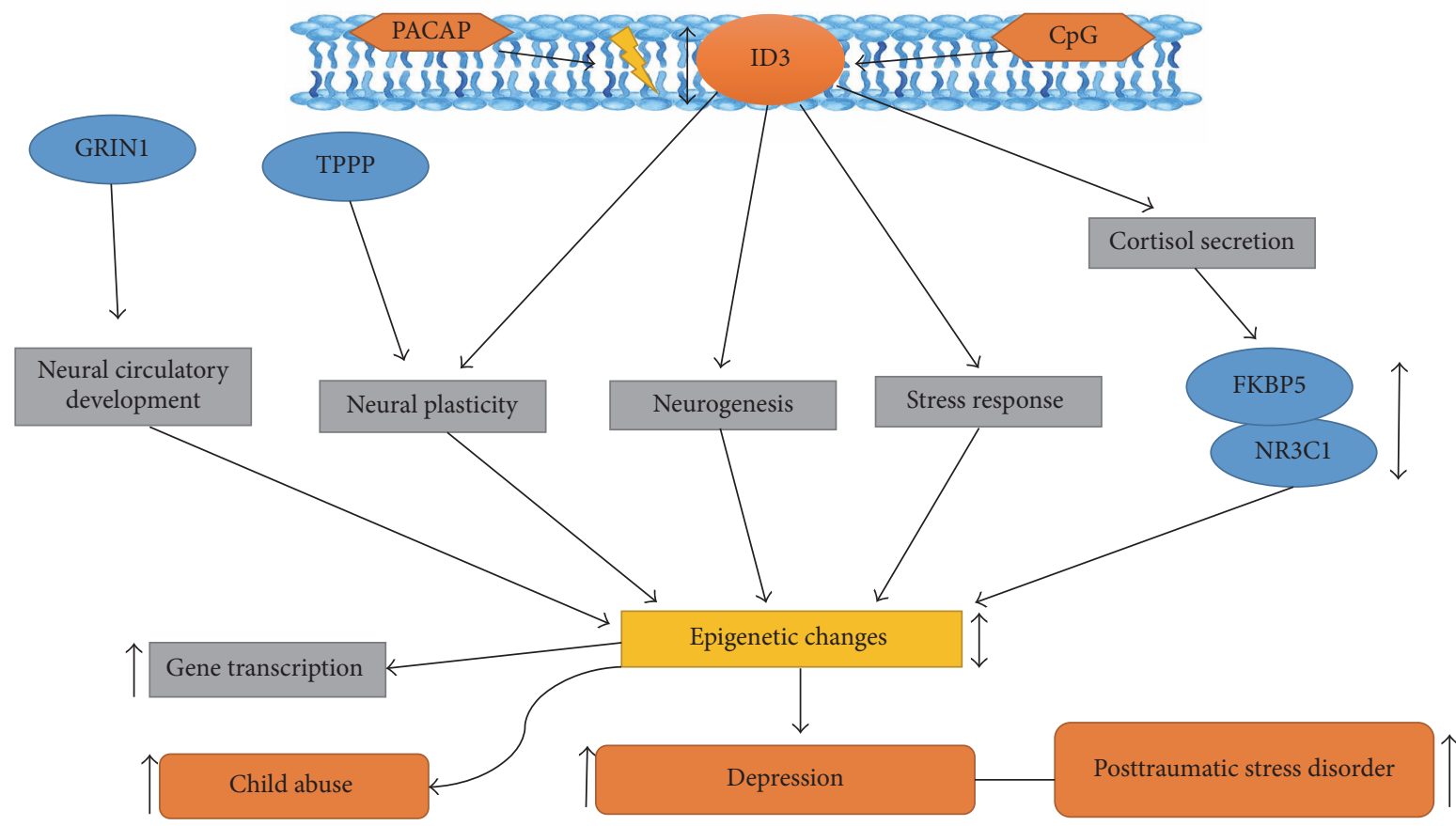

(a) Epigenetic mechanism of ID3 in neurological disorders. Summary of ID3 involvement in neurological disorders is presented

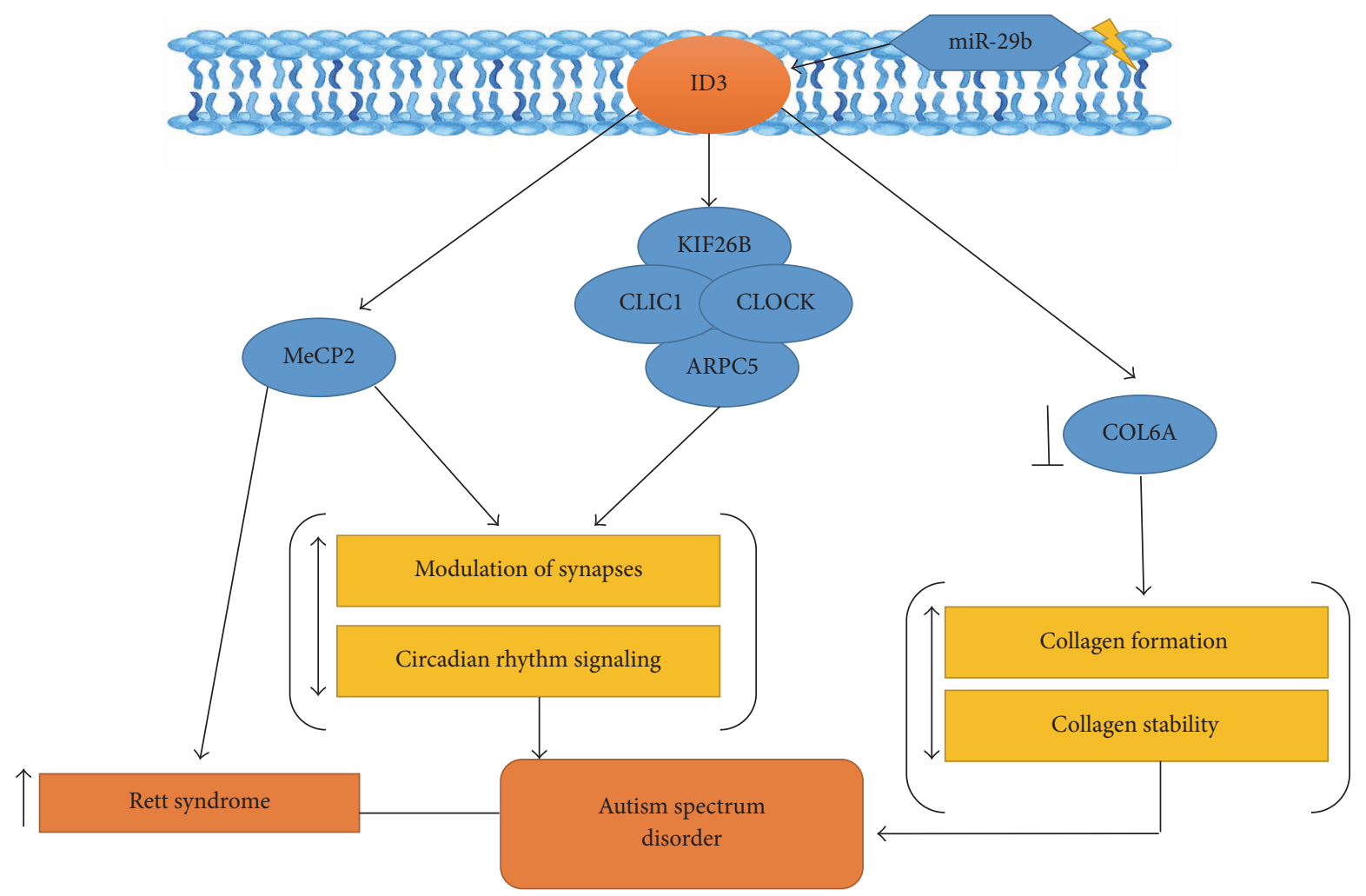

(b) ID3 signaling pathway proposed in development of autism spectrum disorder

FIGURE 3

low density lipoproteins $(p=0.0024)$ [85]. C57BL/6 male mice on high fat diets (60\% calorie from fat) develop MetS connected with obesity, elevated plasma glucose, proteinuria, and glomerulonephritis (GN) and this may be due to decrease in renal AMP activated protein kinase, a cellular energy sensor [90]. However, C57BL/6 female mice on high fat diets develop GN and proteinuria only in the absence of ID3 suggesting distinct pathogenic mechanisms between females 


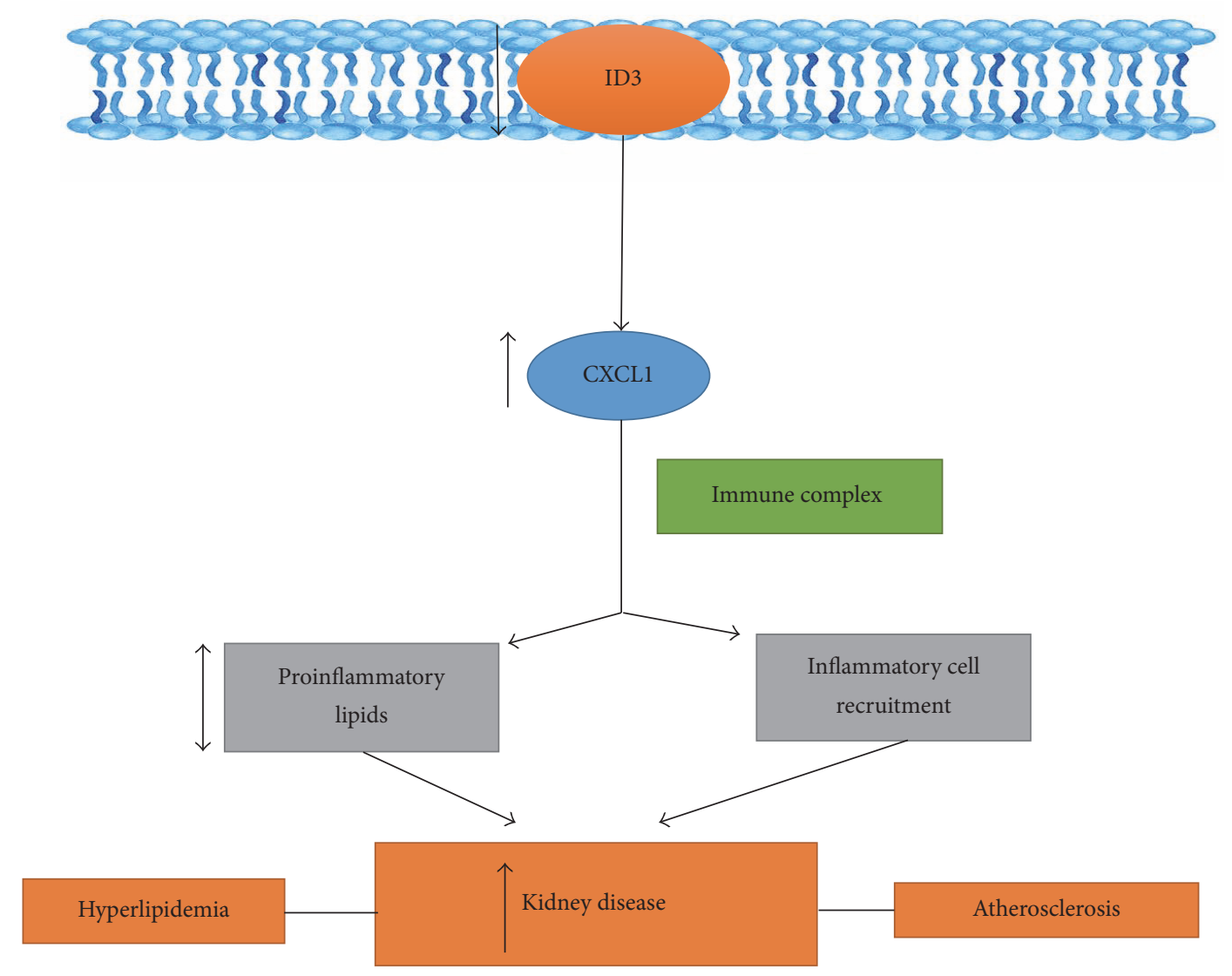

FIGURE 4: ID3 involvement in kidney disease shows a link to hyperlipidemia and atherosclerosis.

and males. Examining molecular mechanisms in mice has recognized ID3 as a unique transcription factor that may contribute to kidney disease and provide mechanistic links between atherosclerosis, hyperlipidemia, and kidney disease in humans. A summary of ID3 pathway contributing to chronic kidney disease is shown in Figure 4.

3.4. Cancer. Deregulation of ID genes is reported in human cancers such as non-small cell lung cancer (NSCLC) and colon cancer. ID3 contributes in generation of hematopoietic stem and progenitor cells (HSPC) associated with myeloproliferative disease (MPD) [91]. ID1 and ID3 associated with the tumor promotion and metastasis [92]. Poor response to chemoradiotherapy has been reported in NSCLC patients with elevated ID1 and ID3 protein expression [92]. Regulation of p21 by ID1 and ID3 has been seen as the vital mechanism inhibiting the accumulation of additional DNA damage and subsequent functional low energy of coloninitiating cells (CC-ICs). Genetic silencing of ID1 and ID3 increases chemotherapy sensitivity in CC-ICs suggesting that these molecules allow cancer cells to be drug resistant [70]. Summary illustration of ID3 signaling involved in various cancer pathways is shown in Figure 5(a).

Glioblastoma multiforme (GBM) tumors contain glioma stem cells or GSCs which are implicated for glioma resistance to treatment [93-97]. ID3 is also shown to be connected with medulloblastoma in children [96]. Inhibition of ID3 reduced proliferation and migration and increased apoptosis of medulloblastoma cells. Potential molecular mechanisms of ID3 in brain cancer are shown in Figure 5(b).

3.5. Bone Disease. Osteogenesis imperfecta (OI) is a condition of fragile or brittle bones that break easily. OI affects 1 in 15,000 live births resulting in recurrent fractures and reduced mobility, with significant influence on quality of life [98]. BMPs (bone morphogenetic proteins) are morphogenetic signaling molecules vital for embryonic modelling. To find molecular understanding into the effect of BMPs on morphogenesis, Hollnagel et al. examined novel genes directly activated by BMP signaling. CDM- (chemically distinct growth medium-) cultured ES cells reacted very stringently to stimulation by numerous activin $\mathrm{A}$, mesoderm inducers (BMP2/4), and fibroblast growth factor [99]. Using cDNA cloning, six BMP target genes were recognized. These include ID3, which exhibited convincing mRNA initiation, and the relatively stimulated Cyr61, DEK, and eIF4AII genes, as well as a gene translating a GC-binding protein. Alongside ID1, ID2, and ID3 genes were initiated by BMP4 in both ES cells and arrangement of various cell lines. ID genes encode negative regulators of basic helix-loop-helix transcription factors. In vivo, ectopic expression was observed of ID3 and Msx2 mRNAs in Ft/1 embryos at intersecting regions of ectopic 


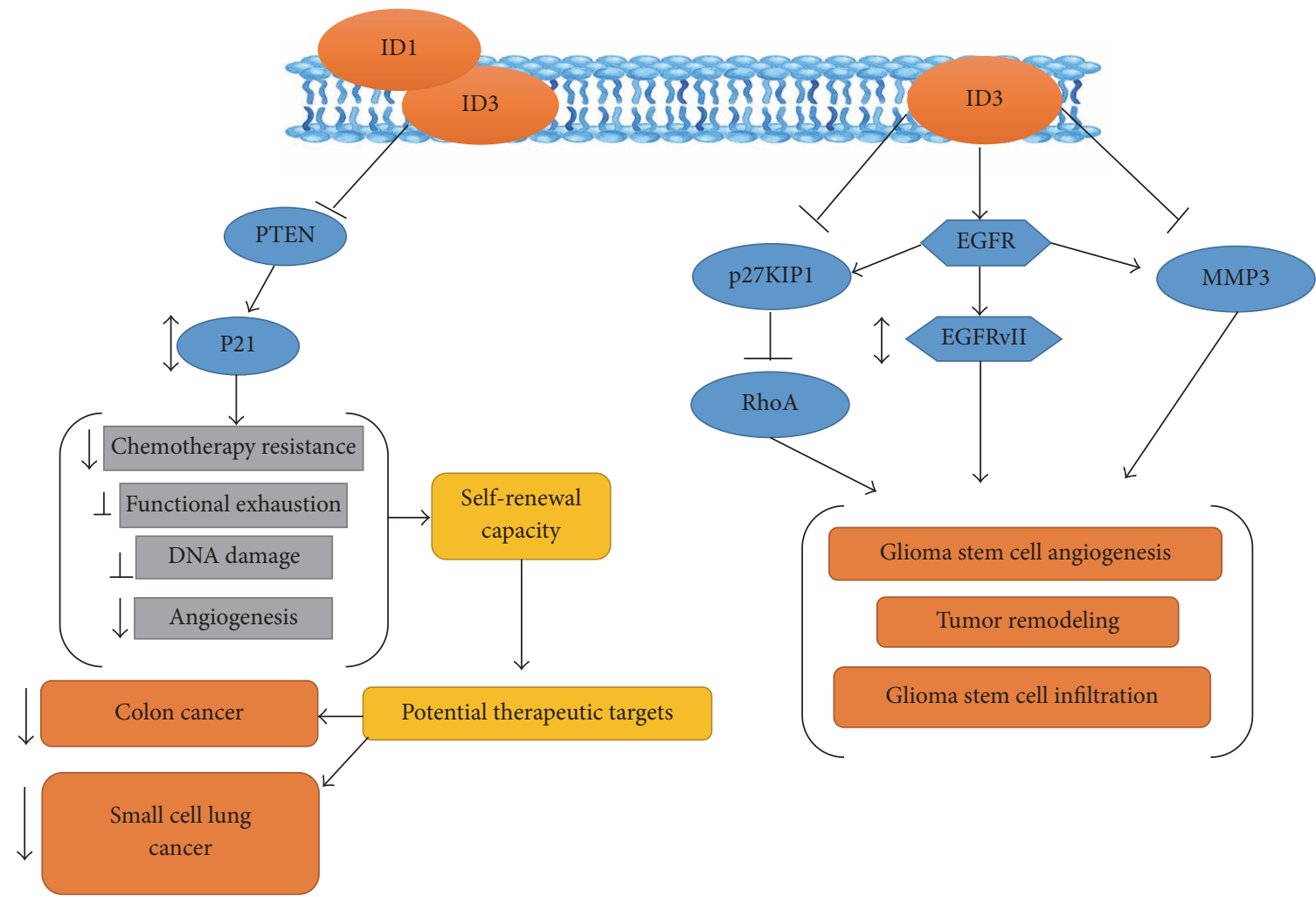

(a) Summary of ID3 signaling pathways involved in colon and lung cancer (left panel). ID3 contribution to tumor angiogenesis in brain cancer (right panel)

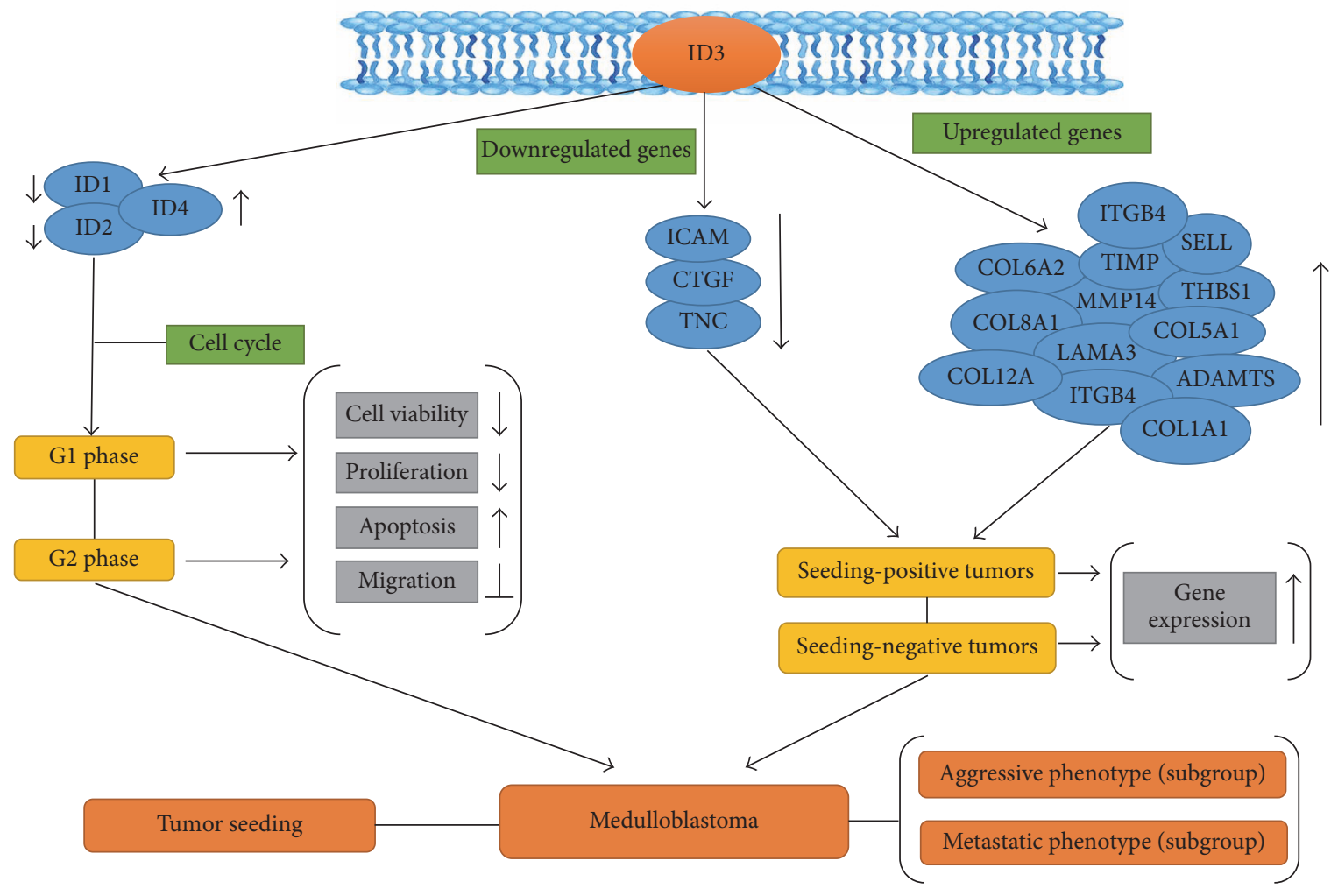

(b) ID3 signaling pathways involved in brain cancer are summarized in the illustration

Figure 5 


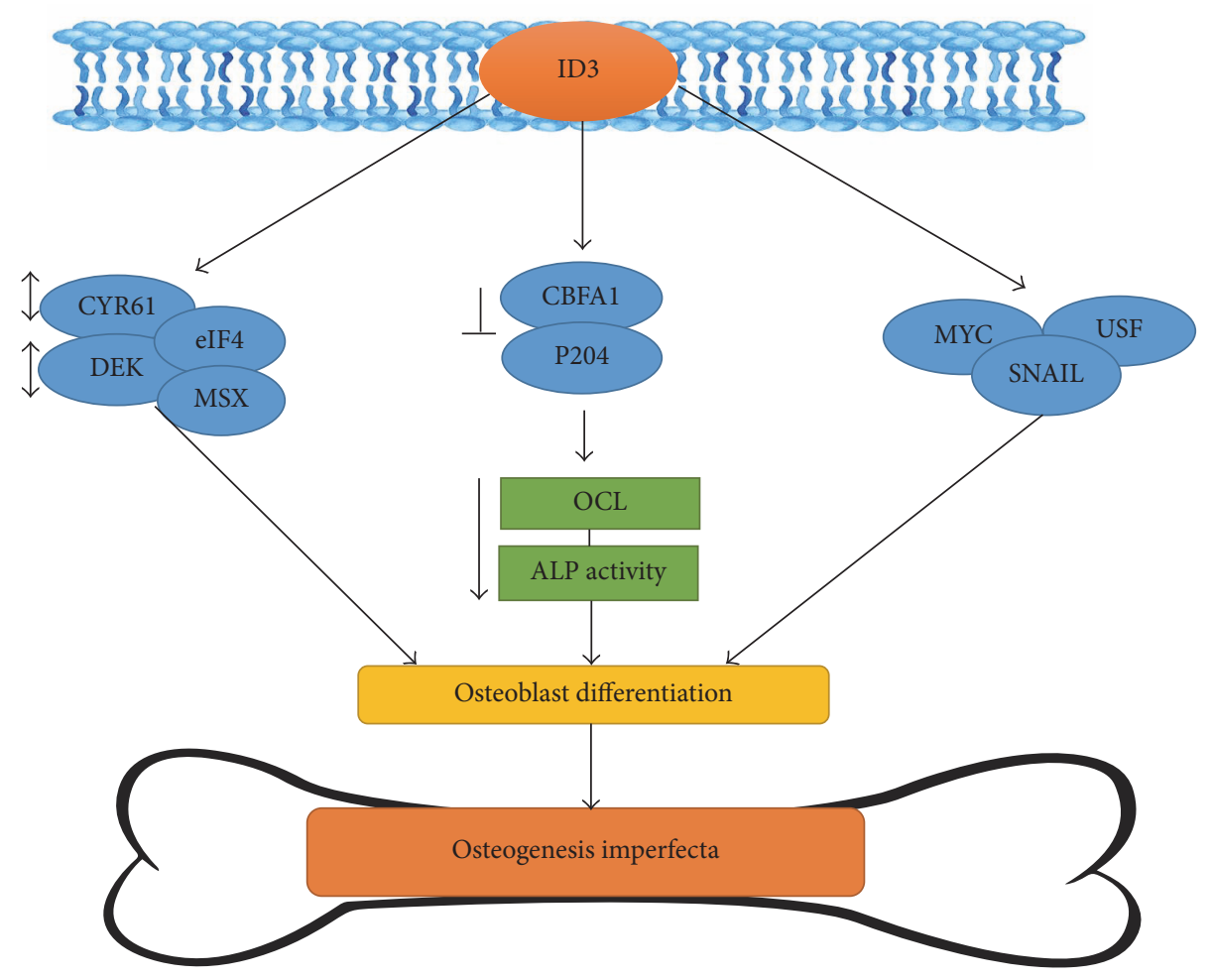

FIGURE 6: ID3 involvement in brittle bone disease pathogenesis described in the summary illustration.

BMP4 misexpression. As a result, Hollnagel et al. proposed that the target genes of BMP4 signaling demonstrated here are part of BMP-stimulated initial processes of mammalian development. The expression arrangements of Msx-1, Msx2, c-jun, ID1, ID2, and ID3 in normal mice versus those lacking in BMP2, BMP4, and BMP2/4-type I receptor will be of distinctive interest to compare. The promoters of the genes recognized in the analysis will aid as valuable tools to illustrate the molecular governing circuits that are overseen by BMP signaling [99].

ID proteins, including ID1, ID2, and ID3, are involved with essential binding factor $\alpha-1$ (Cbfal) to trigger debilitated transcription of the osteocalcin (OCL) and alkaline phosphatase (ALP) gene, commanding to weakened ALP action and osteocalcin (OCL) production. ID acts by hindering the specific-sequence binding of Cbfal to DNA and diminishing the expression of Cbfal in cells experiencing osteogenic differentiation [100]. Summary illustration of ID3 signaling in OI or brittle bone disease is shown in Figure 6. p204, an interferon-inducible protein that acts with both $\mathrm{Cbfal}$ and ID2, debilitated the ID2-mediated inhibition of Cbfa1induced ALP action and OCL production. Luan et al. establish that p204 interrupted the binding of ID2 to Cbfal and facilitated Cbfal to bind to the promoters of its target genes. Furthermore, p204 stimulated the translocation from nucleus to the cytoplasm and enhanced the degradation of ID2 by ubiquitin-proteasome pathway during osteogenesis. Nucleus export signal (NES) of p204 is necessary for the p204enhanced cytoplasmic translocation and degradation of ID2, since a p204 mutant-requiring NES lost these activities.
Taken together, ID proteins help to shape a regulatory circuit and take part to control osteoblast differentiation [100].

ID1 and ID3 function to regulate bone metabolism in vivo [101]. ID1/ID3 heterozygous knockout mice showed that the thickness of calvarial junctions was attenuated by more than $50 \%$ [101]. Suppression of proliferation and mineralization in osteoblasts resultant from ID1/ID3 heterozygous knockout mice was proposed as a mechanism. Moreover, ID1/ID3 heterozygous knockout mice inhibited BMP-stimulated bone development in vivo. Hence, ID1 and ID3 are critical regulators that support bone formation in vivo [101].

The connection between mechanisms of MetS and bone mineral density (BMD) is controversial [102]. Von Muhlen et al. examined the association of MetS with osteoporosis, osteoporotic fractures, and BMD. MetS was associated with decreased, not increased BMD. Frequency of osteoporotic nonvertebral breakages was greater in members with MetS. MetS may be an additional risk factor for osteoporotic fractures [102]. Occurrence of MetS at reference was 23.5\% in men and $18.2 \%$ in women. Age-adjusted analyses demonstrated in both men and women with MetS had increased BMD at total hip when compared to those without MetS $(p<0.001$ and $p=0.01$, resp.). Men not women with MetS furthermore had greater BMD at femoral neck $(p=0.05)$. Subsequently modifying for BMI, these connections were inverted, such that MetS was linked with decreased and not increased BMD. Occurrence of osteoporotic nonvertebral breakages was increased in participants with MetS. The connection of MetS with increased BMD was explained by the increased BMI in those with MetS [102]. 
3.6. Autoimmune Diseases. MetS has been involved in autoimmune diseases. One particular autoimmune disease is primary Sjögren's syndrome ( $\mathrm{pSS}$ ), which is primarily categorized by inflammatory association of the exocrine glands important to dry eye and mouth. Numerous organ systems can be disturbed which can cause a wide variety of extraglandular indicators, such as small airway disorders, multiple sclerosis-like disease, peripheral neuropathy glomerulonephritis, and lymphoma [101]. pSS predominately affects females $(9: 1)$, with a frequency in the overall population from 0.1 to $0.6 \%$. Studies evaluating patients with rheumatoid arthritis (RA) [2] and systemic lupus erythematosus (SLE) [103] have shown that inflammation plays a role in the progression of hypertension, diabetes mellitus, and MetS [104].

The ID3 gene is involved in the growth and function of B and T cells. Deficient ID3 mice develop autoimmune disease comparable to human primary Sjögren's syndrome (pSS). Together B and T lymphocytes have been involved to contribute to the disease phenotype in this model [105]. The upregulation of ID1 and ID3 genes has been reported in patients with rheumatoid arthritis (RA) [106]. Elevated expression of ID1 and ID3 in endothelial cells has been proposed to contribute to severe angiogenesis found in RA.

\section{Conclusion}

We have comprehensively reviewed the existing evidence to illustrate the association between ID3 and metabolic perturbations. Furthermore, we extended this understanding of how ID3 and metabolic perturbations by environmental factors such as EDCs can modify chronic disease risk and health outcomes. ID3 has been seen to interact with multiple diseases such as cancer, vascular, neurological, autoimmune, and bone diseases. Epidemiological and animal model studies have shown connections between ID3 and metabolic perturbations in chronic disease. Research is warranted to better define the influence of EDCs to ID3-induced metabolic perturbations. This may lead to novel pathways for how the interaction of ID3, EDCs, and metabolic disorders exacerbates complex chronic disease and can help public health professionals control these metabolic disorders.

\section{Conflicts of Interest}

The authors declare that they have no conflicts of interest.

\section{References}

[1] Q. Felty and N. Porther, "Estrogen-induced redox sensitive Id3 signaling controls the growth of vascular cells," Atherosclerosis, vol. 198, no. 1, pp. 12-21, 2008.

[2] D. Sakurai, N. Tsuchiya, A. Yamaguchi et al., "Crucial role of inhibitor of DNA binding/differentiation in the vascular endothelial growth factor-induced activation and angiogenic processes of human endothelial cells," Journal of Immunology, vol. 173, no. 9, pp. 5801-5809, 2004.
[3] G. Eelen, P. De Zeeuw, M. Simons, and P. Carmeliet, "Endothelial cell metabolism in normal and diseased vasculature," Circulation Research, vol. 116, no. 7, pp. 1231-1244, 2015.

[4] Y. He, Y. Yao, S. E. Tsirka, and Y. Cao, "Cell-culture models of the blood-brain barrier," Stroke, vol. 45, no. 8, pp. 2514-2526, 2014.

[5] A. Cutchins, D. B. Harmon, J. L. Kirby et al., "Inhibitor of differentiation-3 mediates high fat diet-induced visceral fat expansion," Arteriosclerosis, Thrombosis, and Vascular Biology, vol. 32, no. 2, pp. 317-324, 2012.

[6] A. C. Doran, N. Meller, A. Cutchins et al., "The helix-loophelix factors Id3 and E47 are novel regulators of adiponectin," Circulation Research, vol. 103, no. 6, pp. 624-634, 2008.

[7] E. E. Hatch, J. W. Nelson, R. W. Stahlhut, and T. F. Webster, "Association of endocrine disruptors and obesity: perspectives from epidemiological studies," International Journal of Andrology, vol. 33, no. 2, pp. 324-331, 2010.

[8] E. Swedenborg, J. Rüegg, S. Mäkelä, and I. Pongratz, "Endocrine disruptive chemicals: mechanisms of action and involvement in metabolic disorders," Journal of Molecular Endocrinology, vol. 43, no. 1, pp. 1-10, 2009.

[9] C. Casals-Casas and B. Desvergne, "Endocrine disruptors: From endocrine to metabolic disruption," Annual Review of Physiology, vol. 73, pp. 135-162, 2011.

[10] J. K. Das and Q. Felty, "PCB153-induced overexpression of ID3 contributes to the development of microvascular lesions," PLOS ONE, vol. 9, no. 8, Article ID e104159, 2014.

[11] Q. Felty, "Proteomic 2D DIGE profiling of human vascular endothelial cells exposed to environmentally relevant concentration of endocrine disruptor PCB153 and physiological concentration of $17 \beta$-estradiol," Cell Biology and Toxicology, vol. 27, no. 1, pp. 49-68, 2011.

[12] D. Lyden, A. Z. Young, D. Zagzag et al., "Id1 and Id3 are required for neurogenesis, angiogenesis and vascularization of tumour xenografts," Nature, vol. 401, no. 6754, pp. 670-677, 1999.

[13] J. Yang, X. Li, and N. W. Morrell, "Id proteins in the vasculature: From molecular biology to cardiopulmonary medicine," Cardiovascular Research, vol. 104, no. 3, pp. 388-398, 2014.

[14] A. Lasorella, R. Benezra, and A. Iavarone, “The ID proteins: Master regulators of cancer stem cells and tumour aggressiveness," Nature Reviews Cancer, vol. 14, no. 2, pp. 77-91, 2014.

[15] L. Pan, S. Sato, J. P. Frederick, X.-H. Sun, and Y. Zhuang, "Impaired immune responses and B-cell proliferation in mice lacking the Id 3 gene," Molecular and Cellular Biology, vol. 19, no. 9, pp. 5969-5980, 1999.

[16] P. Poulsen, A. Vaag, K. Kyvik, and H. Beck-Nielsen, "Genetic versus environmental aetiology of the metabolic syndrome among male and female twins," Diabetologia, vol. 44, no. 5, pp. 537-543, 2001.

[17] D. Fraidenraich, E. Stillwell, E. Romero et al., "Rescue of cardiac defects in Id knockout embryos by injection of embyonic stem cells," Science, vol. 306, no. 5694, pp. 247-252, 2004.

[18] R. W.-S. Lim and J.-M. Wu, "Molecular mechanisms regulating expression and function of transcription regulator "inhibitor of differentiation 3"," Acta Pharmacologica Sinica, vol. 26, no. 12, pp. 1409-1420, 2005.

[19] A. Lasorella, T. Uo, and A. Iavarone, "Id proteins at the crossroad of development and cancer," Oncogene, vol. 20, no. 58, pp. 8326-8333, 2001.

[20] C. Mueller, S. Baudler, H. Welzel, M. Böhm, and G. Nickenig, "Identification of a novel redox-sensitive gene, Id3, which mediates Angiotensin II-induced cell growth," Circulation, vol. 105, no. 20, pp. 2423-2428, 2002. 
[21] J. K. Das and Q. Felty, "Microvascular Lesions by EstrogenInduced ID3: Its Implications in Cerebral and Cardiorenal Vascular Disease," Journal of Molecular Neuroscience, vol. 55, no. 3, pp. 618-631, 2014.

[22] D. A. Loveys, M. B. Streiff, and G. J. Kato, "E2A basic-helix-loophelix transcription factors are negatively regulated by serum growth factors and by the Id3 protein," Nucleic Acids Research, vol. 24, no. 14, pp. 2813-2820, 1996.

[23] Y. Liu, M. Encinas, J. X. Comella, M. Aldea, and C. Gallego, "Basic Helix-Loop-Helix Proteins Bind to TrkB and p21Cip1 Promoters Linking Differentiation and Cell Cycle Arrest in Neuroblastoma Cells," Molecular and Cellular Biology, vol. 24, no. 7, pp. 2662-2672, 2004.

[24] C. J. Sherr and J. M. Roberts, "Inhibitors of mammalian G1 cyclin-dependent kinases," Genes \& Development, vol. 9, no. 10, pp. 1149-1163, 1995.

[25] S. Forrest and C. McNamara, "Id family of transcription factors and vascular lesion formation," Arteriosclerosis, Thrombosis, and Vascular Biology, vol. 24, no. 11, pp. 2014-2020, 2004.

[26] A. M. Taylor, F. Li, P. Thimmalapura et al., "Hyperlipemia and oxidation of LDL induce vascular smooth muscle cell growth: An effect mediated by the HLH factor Id3," Journal of Vascular Research, vol. 43, no. 2, pp. 123-130, 2006.

[27] K. Langlands, X. Yin, G. Anand, and E. V. Prochownik, "Differential interactions of Id proteins with basic-helix-loophelix transcription factors," Journal of Biological Chemistry, vol. 272, no. 32, pp. 19785-19793, 1997.

[28] J. K. Das, N. F. Voelkel, and Q. Felty, "ID3 contributes to the acquisition of molecular stem cell-like signature in microvascular endothelial cells: Its implication for understanding microvascular diseases," Microvascular Research, vol. 98, pp. 126-138, 2015.

[29] Y. Ji, Z. Pos, M. Rao et al., "Repression of the DNA-binding inhibitor Id 3 by Blimp-1 limits the formation of memory CD8 + T cells," Nature Immunology, vol. 12, no. 12, pp. 1230-1237, 2011.

[30] X. Zhang, M.-T. Ling, Q. Wang et al., "Identification of a novel Inhibitor of Differentiation-1 (ID-1) binding partner, caveolin-1, and its role in epithelial-mesenchymal transition and resistance to apoptosis in prostate cancer cells," Journal of Biological Chemistry, vol. 282, no. 46, pp. 33284-33294, 2007.

[31] Y. Arita, S. Kihara, N. Ouchi et al., "Paradoxical decrease of an adipose-specific protein, adiponectin, in obesity," Biochemical and Biophysical Research Communications, vol. 257, no. 1, pp. 79-83, 1999.

[32] G. R. Steinberg and B. E. Kemp, "AMPK in health and disease," Physiological Reviews, vol. 89, no. 3, pp. 1025-1078, 2009.

[33] B. M. Wice, E. Bernal-Mizrachi, and M. A. Permutt, "Glucose and other insulin secretagogues induce, rather than inhibit, expression of Id-1 and Id-3 in pancreatic islet beta cells," Diabetologia, vol. 44, no. 4, pp. 453-463, 2001.

[34] S.-H. Lee, E. Hao, F. Levine, and P. Itkin-Ansari, "Id3 upregulates BrdU incorporation associated with a DNA damage response, not replication, in human pancreatic $\beta$-cells," Islets, vol. 3 , no. 6 , pp. 358-366, 2011.

[35] E. S. Ford, W. H. Giles, and W. H. Dietz, "Prevalence of the metabolic syndrome among US adults: findings from the Third National Health and Nutrition Examination Survey," Journal of the American Medical Association, vol. 287, no. 3, pp. 356-359, 2002.

[36] C. L. Edwardson, T. Gorely, M. J. Davies et al., "Association of sedentary behaviour with metabolic syndrome: A metaanalysis," PLoS ONE, vol. 7, no. 4, Article ID e34916, 2012.
[37] V.S. Malik, B. M. Popkin, G. A. Bray, J.-P. Després, W. C. Willett, and F. B. Hu, "Sugar-sweetened beverages and risk of metabolic syndrome and type 2 diabetes: a meta-analysis," Diabetes Care, vol. 33, no. 11, pp. 2477-2483, 2010.

[38] R. L. Pollex and R. A. Hegele, "Genetic determinants of the metabolic syndrome," Nature Clinical Practice Cardiovascular Medicine, vol. 3, no. 9, pp. 482-489, 2006.

[39] J. L. Kaplan, M. A. Marshall, C. C. McSkimming et al., "Adipocyte progenitor cells initiate monocyte chemoattractant protein-1-mediated macrophage accumulation in visceral adipose tissue," Molecular Metabolism, vol. 4, no. 11, pp. 779-794, 2015.

[40] J. Panee, "Monocyte Chemoattractant Protein 1 (MCP-1) in obesity and diabetes," Cytokine, vol. 60, no. 1, pp. 1-12, 2012.

[41] X. Jin, J. Yin, S.-H. Kim et al., "EGFR-AKT-Smad signaling promotes formation of glioma stem-like cells and tumor angiogenesis by ID3-driven cytokine induction," Cancer Research, vol. 71, no. 22, pp. 7125-7134, 2011.

[42] H. M. Perry, S. N. Oldham, S. P. Fahl et al., "Helix-loophelix factor inhibitor of differentiation 3 regulates interleukin5 expression and B-1a B cell proliferation," Arteriosclerosis, Thrombosis, and Vascular Biology, vol. 33, no. 12, pp. 2771-2779, 2013.

[43] P.-L. Kuo, J.-Y. Hung, S.-K. Huang et al., "Lung cancer-derived galectin-1 mediates dendritic cell anergy through inhibitor of DNA binding 3/IL-10 signaling pathway," Journal of Immunology, vol. 186, no. 3, pp. 1521-1530, 2011.

[44] C. J. Mattingly, G. T. Colby, M. C. Rosenstein, J. N. Forrest Jr., and J. L. Boyer, "Promoting comparative molecular studies in environmental health research: An overview of the comparative toxicogenomics database (CTD)," Pharmacogenomics Journal, vol. 4, no. 1, pp. 5-8, 2004.

[45] X. Jin, X. Jin, Y.-W. Sohn et al., "Blockade of EGFR signaling promotes glioma stem-like cell invasiveness by abolishing ID3mediated inhibition of p27KIP1 and MMP3 expression," Cancer Letters, vol. 328, no. 2, pp. 235-242, 2013.

[46] A. G. Kirkley and R. M. Sargis, "Environmental endocrine disruption of energy metabolism and cardiovascular risk," Current Diabetes Reports, vol. 14, article 494, 2014.

[47] F. Ariemma, V. D’Esposito, D. Liguoro et al., "Low-Dose bisphenol-A impairs adipogenesis and generates dysfunctional 3T3-L1 adipocytes," PLoS ONE, vol. 11, no. 3, Article ID e0150762, 2016.

[48] S. Savastano, G. Tarantino, V. D’Esposito et al., "BisphenolA plasma levels are related to inflammatory markers, visceral obesity and insulin-resistance: A cross-sectional study on adult male population," Journal of Translational Medicine, vol. 13, no. 1, article no. 169, 2015.

[49] H. Uemura, K. Arisawa, M. Hiyoshi et al., "Prevalence of metabolic syndrome associated with body burden levels of dioxin and related compounds among Japan's general population," Environmental Health Perspectives, vol. 117, no. 4, pp. 568573, 2009.

[50] B. Wahlang, K. C. Falkner, B. Gregory et al., "Polychlorinated biphenyl 153 is a diet-dependent obesogen that worsens nonalcoholic fatty liver disease in male C57BL6/J mice," The Journal of Nutritional Biochemistry, vol. 24, no. 9, pp. 1587-1595, 2013.

[51] L. M. Grønning, R. Tingsabadh, K. Hardy et al., "Glucose induces increases in levels of the transcriptional repressor Id2 via the hexosamine pathway," American Journal of Physiology-Endocrinology and Metabolism, vol. 290, no. 4, pp. E599-E606, 2006. 
[52] J. Bitman and H. C. Cecil, "Estrogenic activity of DDT analogs and polychlorinated biphenyls," Journal of Agricultural and Food Chemistry, vol. 18, no. 6, pp. 1108-1112, 1970.

[53] J. C. Davey, J. E. Bodwell, J. A. Gosse, and J. W. Hamilton, "Arsenic as an endocrine disruptor: Effects of arsenic on estrogen receptor-mediated gene expression in vivo and in cell culture," Toxicological Sciences, vol. 98, no. 1, pp. 75-86, 2007.

[54] M. D. Meek and G. L. Finch, "Diluted mainstream cigarette smoke condensates activate estrogen receptor and aryl hydrocarbon receptor-mediated gene transcription," Environmental Research, vol. 80, no. 1, pp. 9-17, 1999.

[55] S. Tavolari, L. Bucci, V. Tomasi, and T. Guarnieri, "Selected polychlorobiphenyls congeners bind to estrogen receptor alpha in human umbilical vascular endothelial (HUVE) cells modulating angiogenesis," Toxicology, vol. 218, no. 1, pp. 67-74, 2006.

[56] T. Wada, J. Gao, and W. Xie, "PXR and CAR in energy metabolism," Trends in Endocrinology and Metabolism, vol. 20, no. 6, pp. 273-279, 2009.

[57] P. Gustavsson and C. Hogstedt, "A cohort study of Swedish capacitor manufacturing workers exposed to polychlorinated biphenyls (PCBs)," American Journal of Industrial Medicine, vol. 32, no. 3, pp. 234-239, 1997.

[58] A. Goncharov, M. Pavuk, H. R. Foushee, and D. O. Carpenter, "Blood pressure in relation to concentrations of PCB congeners and Chlorinated pesticides," Environmental Health Perspectives, vol. 119, no. 3, pp. 319-325, 2011.

[59] A. Hay and J. Tarrel, "Mortality of power workers exposed to phenoxy herbicides and polychlorinated biphenyls in waste transformer oil," Annals of the New York Academy of Sciences, vol. 837, pp. 138-156, 1997.

[60] A. V. Sergeev and D. O. Carpenter, "Hospitalization rates for coronary heart disease in relation to residence near areas contaminated with persistent organic pollutants and other pollutants," Environmental Health Perspectives, vol. 113, no. 6, pp. 756-761, 2005.

[61] S. Tokunaga and K. Kataoka, "A longitudinal analysis on the association of serum lipids and lipoproteins concentrations with blood polychlorinated biphenyls level in chronic "Yusho" patients," Fukuoka Igaku Zasshi, vol. 94, no. 5, pp. 110-117, 2003.

[62] R. Amanchy, B. Periaswamy, S. Mathivanan, R. Reddy, S. G. Tattikota, and A. Pandey, "A curated compendium of phosphorylation motifs [4]," Nature Biotechnology, vol. 25, no. 3, pp. 285286, 2007.

[63] S. K. Chakrabarti, B. K. Cole, Y. Wen, S. R. Keller, and J. L. Nadler, "12/15-Lipoxygenase products induce inflammation and impair insulin signaling in 3t3-l1 adipocytes," Obesity, vol. 17, no. 9, pp. 1657-1663, 2009.

[64] A. M. Taylor, R. Hanchett, R. Natarajan et al., "The effects of leukocyte-type 12/15-lipoxgenase on Id3-mediated vascular smooth muscle cell growth," Arterioscler Thromb Vasc Biol, vol. 25, no. 10, pp. 2069-2074, 2005.

[65] A. C. Doran, A. B. Lehtinen, N. Meller et al., "Id3 Is a novel atheroprotective factor containing a functionally significant single-nucleotide polymorphism associated with intima-media thickness in humans," Circulation Research, vol. 106, no. 7, pp. 1303-1311, 2010.

[66] A. Manichaikul, S. S. Rich, H. Perry, J. Yeboah, M. Law et al., "A functionally significant polymorphism in ID3 is associated with human coronary pathology," PLoS ONE, vol. 9, article e90222, no. 3, 2014.

[67] J. Yang, X. Li, Y. Li et al., "Id proteins are critical downstream effectors of BMP signaling in human pulmonary arterial smooth muscle cells," American Journal of Physiology - Lung Cellular and Molecular Physiology, vol. 305, no. 4, pp. L312-L321, 2013.

[68] A. P. Owens, Angiotensin II induction of regional effects in murine vasculature [Ph.D. thesis], University of Kentucky Doctoral Dissertations, Williamsburg, Ky, USA, 2009.

[69] J.-H. Kim, M. R. Peacock, S. C. George, and C. C. W. Hughes, "BMP9 induces EphrinB2 expression in endothelial cells through an Alk1-BMPRII/ActRII-ID1/ID3-dependent pathway: Implications for hereditary hemorrhagic telangiectasia type II," Angiogenesis, vol. 15, no. 3, pp. 497-509, 2012.

[70] C. A. O'Brien, A. Kreso, P. Ryan et al., "ID1 and ID3 Regulate the Self-Renewal Capacity of Human Colon Cancer-Initiating Cells through p21," Cancer Cell, vol. 21, no. 6, pp. 777-792, 2012.

[71] V. Solozobova, N. Wyvekens, and J. Pruszak, "Lessons from the embryonic neural stem cell niche for neural lineage differentiation of pluripotent stem cells," Stem Cell Reviews and Reports, vol. 8, no. 3, pp. 813-829, 2012.

[72] J. L. Montalvo-Ortiz, K. A. Bordner, B. C. Carlyle, J. Gelernter, A. A. Simen, and J. Kaufman, "The role of genes involved in stress, neural plasticity, and brain circuitry in depressive phenotypes: Convergent findings in a mouse model of neglect," Behavioural Brain Research, vol. 315, pp. 71-74, 2016.

[73] V. Campos-Peña, D. Toral-Rios, F. Becerril-Pérez et al., "Metabolic Syndrome as a Risk Factor for Alzheimer's Disease: Is $\mathrm{A} \beta$ a Crucial Factor in Both Pathologies?" Antioxidants \& Redox Signaling, vol. 26, no. 10, pp. 542-560, 2016.

[74] N. Weder, H. Zhang, K. Jensen et al., "Child abuse, depression, and methylation in genes involved with stress, neural plasticity, and brain circuitry," Journal of the American Academy of Child and Adolescent Psychiatry, vol. 53, no. 4, pp. 417-e5, 2014.

[75] T. Sarachana, R. Zhou, G. Chen, H. K. Manji, and V. W. $\mathrm{Hu}$, "Investigation of post-transcriptional gene regulatory networks associated with autism spectrum disorders by microRNA expression profiling of lymphoblastoid cell lines," Genome Medicine, vol. 2, no. 4, article no. 23, 2010.

[76] S. Peddada, D. H. Yasui, and J. M. LaSalle, "Inhibitors of differentiation (ID1, ID2, ID3 and ID4) genes are neuronal targets of MeCP2 that are elevated in Rett syndrome," Human Molecular Genetics, vol. 15, no. 12, pp. 2003-2014, 2006.

[77] D. A. Rossignol, S. J. Genuis, and R. E. Frye, "Environmental toxicants and autism spectrum disorders: a systematic review," Translational Psychiatry, vol. 4, article e360, 2014.

[78] L. P. Heilbrun, R. F. Palmer, C. R. Jaen, M. D. Svoboda, C. S. Miller, and J. Perkins, "Maternal chemical and drug intolerances: Potential risk factors for autism and attention deficit hyperactivity disorder (ADHD)," Journal of the American Board of Family Medicine, vol. 28, no. 4, pp. 461-470, 2015.

[79] Y.-C. J. Chen, M.-L. M. Yu, W. J. Rogan, B. C. Gladen, and C.C. Hsu, "A 6-year follow-up of behavior and activity disorders in the Taiwan Yu- cheng children," American Journal of Public Health, vol. 84, no. 3, pp. 415-421, 1994.

[80] Endocrine Disruptors, Environmental Health Topics, NIH National Institute of Environmental Health Sciences, http:// www.niehs.nih.gov/.

[81] C. E. Shanahan, S. N. Spak, A. Martinez, and K. C. Hornbuckle, "Inventory of PCBs in Chicago and Opportunities for Reduction in Airborne Emissions and Human Exposure," Environmental Science and Technology, vol. 49, no. 23, pp. 13878-13888, 2015. 
[82] S. Genc, Z. Zadeoglulari, S. H. Fuss, and K. Genc, "The adverse effects of air pollution on the nervous system," Journal of Toxicology, vol. 2012, Article ID 782462, 23 pages, 2012.

[83] M. Kundakovic, K. Gudsnuk, J. B. Herbstman, D. Tang, F. P. Perera, and F. A. Champagne, "DNA methylation of BDNF as a biomarker of early-life adversity," Proceedings of the National Academy of Sciences of the United States of America, vol. 112, no. 22, pp. 6807-6813, 2015.

[84] F. Perera and J. Herbstman, "Prenatal environmental exposures, epigenetics, and disease," Reproductive Toxicology, vol. 31, no. 3 , pp. 363-373, 2011.

[85] C. Tenger and X. Zhou, "Apolipoprotein E modulates immune activation by acting on the antigen-presenting cell," Immunology, vol. 109, no. 3, pp. 392-397, 2003.

[86] D. J. Lynn, C. Chan, M. Naseer et al., "Curating the innate immunity interactome," BMC Systems Biology, vol. 4, article no. 117, 2010.

[87] D. Nackiewicz, P. Dey, B. Szczerba et al., "Inhibitor of differentiation 3, a transcription factor, regulates hyperlipidemiaassociated kidney disease," Nephron - Experimental Nephrology, vol. 126, no. 3, pp. 141-147, 2014.

[88] Q. Zhao, C. Chang, J. P. Gonzalez, K. Alzahrani, J. L. Button, and D. Fraidenraich, "Combined Id1 and Id3 deletion leads to severe erythropoietic disturbances," PLoS ONE, vol. 11, no. 4, Article ID e0154480, 2016.

[89] J.-H. Liu, S.-Y. Lin, C.-Y. Hsu et al., “The risk for chronic kidney disease in patients with heart diseases: A 7-year follow-up in a cohort study in Taiwan," BMC Nephrology, vol. 13, no. 1, article no. 77, 2012.

[90] A.-E. Declèves, A. V. Mathew, R. Cunard, and K. Sharma, "AMPK mediates the initiation of kidney disease induced by a high-fat diet," Journal of the American Society of Nephrology, vol. 22, no. 10, pp. 1846-1855, 2011.

[91] J. K. Keller, "Molecular cellular regulation of hematopoiesis, National Cancer Institute Division of Basic Sciences," http:// grantome.com/grant/NIH/ZIA-BC010001-17.

[92] E. Castañon, J. Bosch-Barrera, I. López et al., "Id1 and Id3 co-expression correlates with clinical outcome in stage III$\mathrm{N} 2$ non-small cell lung cancer patients treated with definitive chemoradiotherapy," Journal of Translational Medicine, vol. 11, no. 1, article no. 13, 2013.

[93] S. Bao, Q. Wu, R. E. McLendon et al., "Glioma stem cells promote radioresistance by preferential activation of the DNA damage response," Nature, vol. 444, no. 7120, pp. 756-760, 2006.

[94] A. J. Chalmers, "Radioresistant glioma stem cells-Therapeutic obstacle or promising target?" DNA Repair, vol. 6, no. 9, pp. 1391-1394, 2007.

[95] I. Nakano and H. I. Kornblum, "Brain tumor stem cells," Pediatric Research, vol. 59, no. 4, 2006.

[96] J. H. Phi, S. A. Choi, S.-H. Lim et al., "ID3 contributes to cerebrospinal fluid seeding and poor prognosis in medulloblastoma," BMC Cancer, vol. 13, article no. 291, 2013.

[97] K. Esposito, P. Chiodini, A. Colao, A. Lenzi, and D. Giugliano, "Metabolic syndrome and risk of cancer: a systematic review and meta-analysis," Diabetes Care, vol. 35, no. 11, pp. 2402-2411, 2012.

[98] M. Balasubramanian, J. Hurst, S. Brown et al., "Compound heterozygous variants in NBAS as a cause of atypical osteogenesis imperfect," Bone, vol. 94, pp. 65-74, 2016.

[99] A. Hollnagel, V. Oehlmann, J. Heymer, U. Rüther, and A. Nordheim, "Id genes are direct targets of bone morphogenetic protein induction in embryonic stem cells," The Journal of Biological Chemistry, vol. 274, no. 28, pp. 19838-19845, 1999.

[100] Y. Luan, X.-P. Yu, N. Yang, S. Frenkel, L. Chen, and C.-J. Liu, "p204 protein overcomes the inhibition of core binding factor $\alpha$-1-mediated osteogenic differentiation by Id helix-loop-helix proteins," Molecular Biology of the Cell, vol. 19, no. 5, pp. 21132126, 2008.

[101] Y. Maeda, K. Tsuji, A. Nifuji, and M. Noda, "Inhibitory helixloop-helix transcription factors Id1/Id3 promote bone formation in vivo," Journal of Cellular Biochemistry, vol. 93, no. 2, pp. 337-344, 2004.

[102] D. Von Muhlen, S. Safii, S. K. Jassal, J. Svartberg, and E. BarrettConnor, "Associations between the metabolic syndrome and bone health in older men and women: The Rancho Bernardo Study," Osteoporosis International, vol. 18, no. 10, pp. 1337-1344, 2007.

[103] N. A. Sinicato, P. A. da Silva Cardoso, and S. Appenzeller, "Risk factors in cardiovascular disease in systemic lupus erythematosus," Current Cardiology Reviews, vol. 9, no. 1, pp. 15-19, 2013.

[104] R. M. R. Pereira, J. F. Carvalho, and E. Bonfá, "Metabolic syndrome in rheumatological diseases," Autoimmunity Reviews, vol. 8, no. 5, pp. 415-419, 2009.

[105] Z. Guo, H. Li, M. Han, T. Xu, X. Wu, and Y. Zhuang, "Modeling Sjögren's syndrome with Id 3 conditional knockout mice," Immunology Letters, vol. 135, no. 1-2, pp. 34-42, 2011.

[106] D. Sakurai, A. Yamaguchi, N. Tsuchiya, K. Yamamoto, and K. Tokunaga, "Expression of ID family genes in the synovia from patients with rheumatoid arthritis," Biochemical and Biophysical Research Communications, vol. 284, no. 2, pp. 436-442, 2001. 

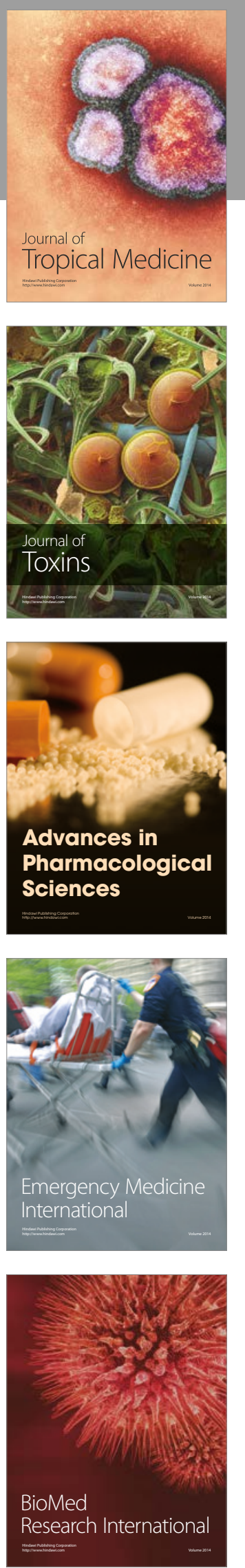
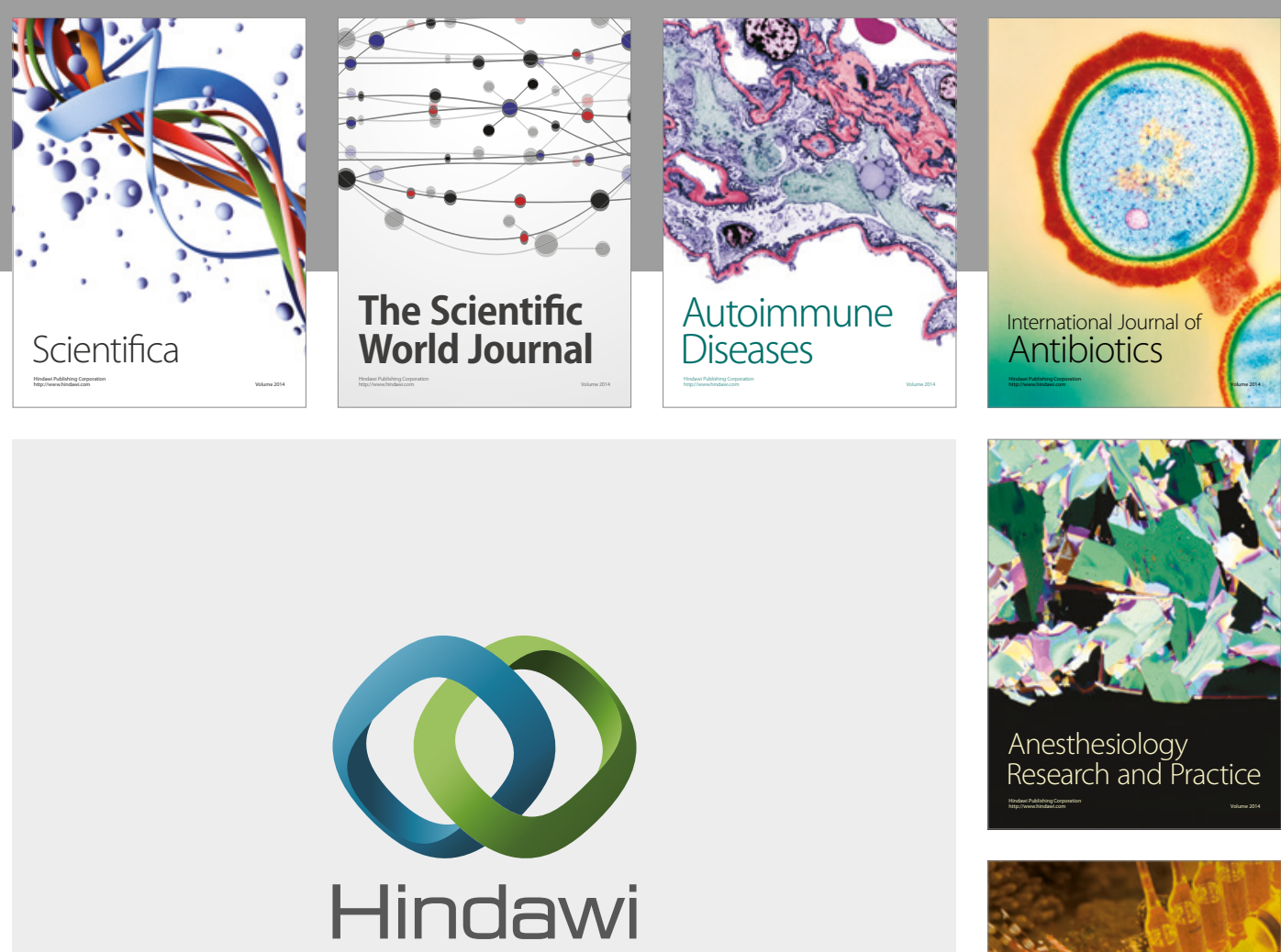

Submit your manuscripts at

https://www.hindawi.com
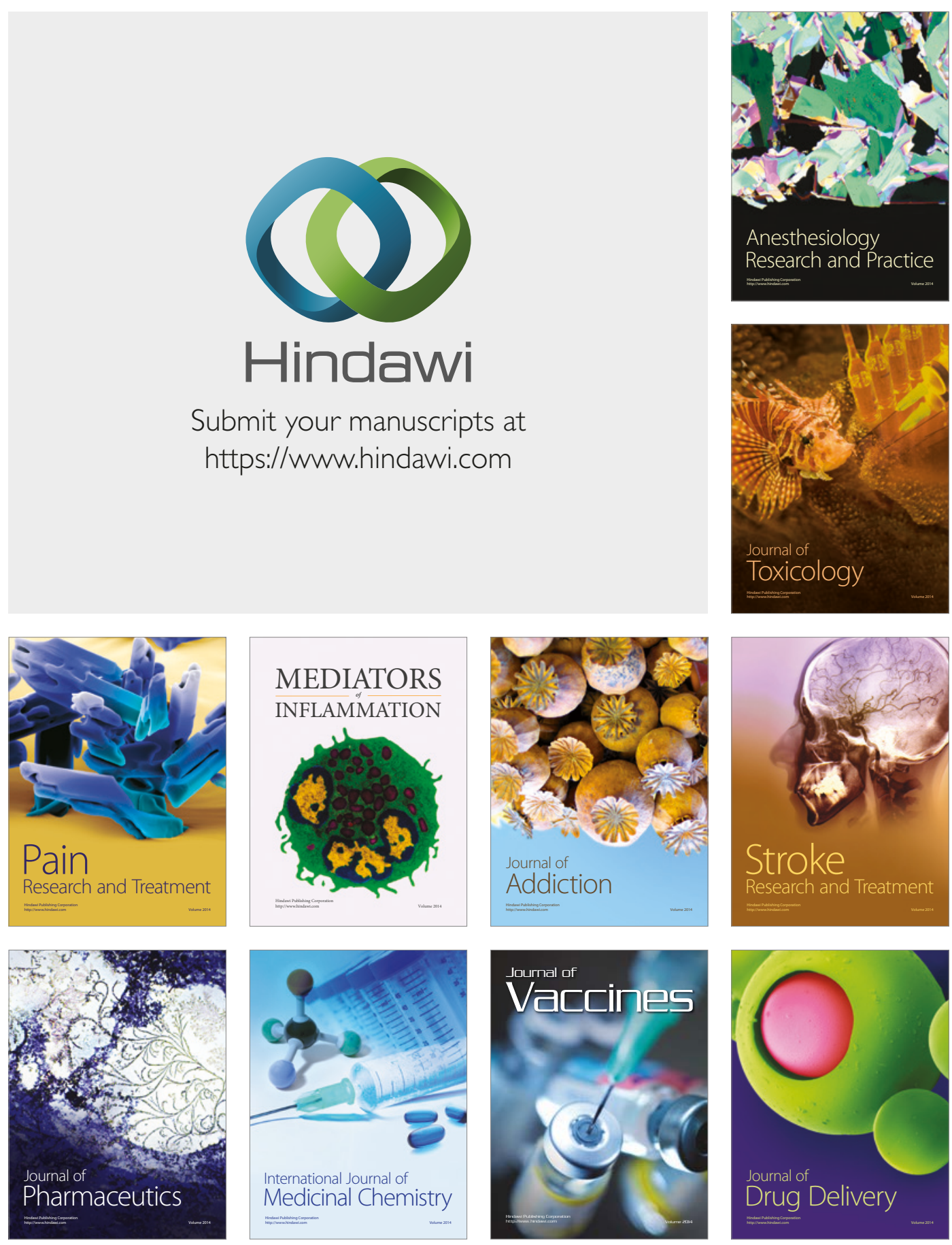